\title{
Article \\ Potential of Essential Oils from Anise, Dill and Fennel Seeds for the Gypsy Moth Control
}

\author{
Igor Kostić $^{1} \mathbb{D}$, Jelica Lazarević ${ }^{2, * \mathbb{D}}$, Darka Šešlija Jovanović ${ }^{2} \mathbb{D}$, Miroslav Kostić $^{3}$, Tatjana Marković ${ }^{3} \mathbb{D}$ \\ and Slobodan Milanović 4,5 (D)
}

1 Institute for Multidisciplinary Research, University of Belgrade, Kneza Višeslava 1, 11030 Belgrade, Serbia; igork@imsi.bg.ac.rs

2 Institute for Biological Research "Siniša Stanković"-National Institute of Republic of Serbia, University of Belgrade, Bulevar Despota Stefana 142, 11060 Belgrade, Serbia; darka.seslija@ibiss.bg.ac.rs

3 Institute for Medicinal Plant Research "Dr Josif Pančić", Tadeuša Košćuška 1, 11000 Belgrade, Serbia; mkostic@mocbilja.rs (M.K.); tmarkovic@mocbilja.rs (T.M.)

4 Faculty of Forestry, University of Belgrade, Kneza Višeslava 1, 11030 Belgrade, Serbia; slobodan.milanovic@sfb.bg.ac.rs or slobodan.milanovic@mendelu.cz

5 Department of Forest Protection and Wildlife Management, Faculty of Forestry and Wood Technology, Mendel University, Zemědělská 3, 61300 Brno, Czech Republic

* Correspondence: jellaz@ibiss.bg.ac.rs

check for

updates

Citation: Kostić, I.; Lazarević, J.; Šešlija Jovanović, D.; Kostić, M.; Marković, T.; Milanović, S. Potential of Essential Oils from Anise, Dill and Fennel Seeds for the Gypsy Moth Control. Plants 2021, 10, 2194. https://doi.org/10.3390/ plants10102194

Academic Editors: Filippo Maggi and Giovanni Benelli

Received: 8 September 2021

Accepted: 11 October 2021

Published: 15 October 2021

Publisher's Note: MDPI stays neutral with regard to jurisdictional claims in published maps and institutional affiliations.

Copyright: (c) 2021 by the authors. Licensee MDPI, Basel, Switzerland. This article is an open access article distributed under the terms and conditions of the Creative Commons Attribution (CC BY) license (https:/ / creativecommons.org/licenses/by/ $4.0 /)$.
Abstract: The gypsy moth (Lymantria dispar L. (Lepidoptera: Erebidae)) is a serious pest of hardwood forests. In the search for an environmentally safe means of its control, we assessed the impact of different concentrations of essential oils (EOs) from the seeds of three Apiaceae plants (anise Pimpinella anisum, dill Anethum graveolens, and fennel Foeniculum vulgare) on behavior, mortality, molting and nutritional physiology of gypsy moth larvae (GML). EOs efficacy was compared with commercial insecticide NeemAzal ${ }^{\circledR}-\mathrm{T} / \mathrm{S}$ (neem). The main compounds in the Eos were trans-anethole in anise; carvone, limonene, and $\alpha$-phellandrene in dill; and trans-anethole and fenchone in fennel seed. At $1 \%$ EOs concentration, anise and fennel were better antifeedants and all three EOs were more toxic than neem. Neem was superior in delaying 2nd to 3rd larval molting. In the 4 th instar, $0.5 \%$, anise and fennel EOs decreased relative consumption rate more than neem, whereas all three EOs were more effective in reducing growth rate, approximate digestibility and efficiency of conversion of food into body mass leading to higher metabolic costs to GML. Decrease in consumption and metabolic parameters compared to control GML confirmed that adverse effects of the EOs stem from both pre- and post-ingestive mechanisms. The results indicate the potential of three EOs to be used for gypsy moth control.

Keywords: botanical insecticide; deterrence coefficient; digestive toxicity; insect pest management; nutritional indices

\section{Introduction}

Gypsy moth Lymantria dispar L. (Lepidoptera: Erebidae) is a polyphagous insect that feeds on over 500 plant species within 73 families, but the most suitable hosts are oaks (Quercus spp.) [1,2]. In Serbia, as well as throughout the Northern Hemisphere, gypsy moth is one of the most serious pests of hardwood forests. Its repeated outbreaks cause enormous damage to trees due to the defoliation leading to the loss of radial growth $[3,4]$ and overall forest decline [5-7]. Gypsy moth outbreaks can also be very injurious in the orchards and urban green space $[8,9]$.

The use of conventional insecticides, often in an inappropriate manner, bears the risk of evolution of insect resistance and may lead to severe environmental disturbances due to pollution and adverse effects on non-target organisms [10-15]. Having this in mind, it is not surprising that many insecticides have been removed from the market. Intensive work is being done to find methods for pest controls that are effective and, at the same 
time, safe for the environment [16-21]. Starting from the 1980s, broad-spectrum persistent insecticides used for gypsy moth control have been replaced with technologies based on entomopathogenic viruses, bacteria, and fungi in addition to mating disruption using sex pheromone traps $[22,23]$. Additionally, plant-based products have been considered as potential control agents [24,25].

Plant secondary metabolites are diverse chemical compounds synthesized through metabolic pathways derived from primary metabolism [26]. Although non-essential for plant growth and reproduction, these compounds confer protection from abiotic and biotic stressors including herbivorous insects [27]. The use of plant products for pest control has a 3000 year long history and they are considered as good candidates for environmentally safe insecticides which would negatively affect insect behavior, physiology, and life-history traits [28-38]. Volatile plant secondary metabolites are used by herbivorous insects to distinguish host from non-host plants [39]. The odor of volatile compounds as well as their taste provokes specific and precise behavioral responses of insects, i.e., movement away (avoidance) from the non-host or movement towards the host plant (attraction) [40]. Besides avoidance behavior induced by odor and taste of secondary plant metabolites, non-host plant compounds may also negatively affect consumption and/or impair the digestion and nutrient absorption, interfere with mitochondrial function, and have toxic, genotoxic, and prooxidant effects [41-50]. These collateral effects caused by secondary metabolites and, among them essential oils, on behavior and insect physiology are the basis for their application as botanical insecticides. High biodegradability, non or low toxicity to mammals and other non-target organisms, as well as slowed down the development of insect resistance make plant secondary metabolites far less dangerous for the environment compared to conventional insecticides [51].

Apiaceae species are rich in essential oils whose insecticidal and repellent activities have been confirmed in many studies on ticks, mosquitoes, cockroaches, stored products, and crop pests [38,52-62]. Studies on Apiaceae EOs activity against forest pests are scarce. Our previous work showed that, by spraying plants with ethanolic solutions of Athamanta haynaldii (Borb. Et Uecht.) the EOs provoked almost three times lower leaf damage by GML than in the control group [63]. This study was aimed to evaluate efficacy of essential oils obtained from seeds of three Apiaceae plant species (anise Pimpinella anisum L., dill Anethum graveolens L., and fennel Foeniculum vulgare Mill.) against GML by assessing their insecticidal and antifeeding activity as well as influence on larval molting, growth and food utilization. It was expected to find a new candidate for developing ecofriendly EO-based insecticide against GML.

\section{Results}

\subsection{Essential Oils Chemical Composition}

Essential oils (EOs) were isolated from seeds of three Apiaceae species-anise, dill, and fennel. Anise seed EO is composed of twelve compounds (one monoterpene hydrocarbon, five oxygenated monoterpenes, three phenylpropanoids, and three sesquiterpene hydrocarbons), among which the most dominant constituent was phenylpropanoid trans-anethol (Table 1, Figure S1). Sixteen compounds were present in the dill seed EO (six monoterpene hydrocarbons, nine oxygenated monoterpenes, and one sesquiterpene hydrocarbon), among which the most common ones were oxygenated monoterpene carvone and monoterpene hydrocarbons limonene and $\alpha$-phellandrene. Fennel seed EO was also composed of sixteen compounds (10 monoterpene hydrocarbons, three oxygenated monoterpenes and three phenylpropanoids), but phenylpropanoid trans-anethol and oxygenated monoterpene fenchone were the major ones. High content of phenylpropanoids and oxygenated monoterpenes was detected in anise (97.66\%) and fennel seed EOs (95.66\%) whereas dill seed EO had lower content of oxygenated compounds $(52.79 \%)$, but higher level of monoterpene hydrocarbons (Table 1). 
Table 1. Chemical composition of essential oils obtained from seeds of anise (Pimpinella anisum), dill (Anethum graveolens) and fennel (Foeniculum vulgare). Compounds are grouped according to their chemical class and total portion of each class is presented in bold. Contents of major compounds are also given in bold. $\mathrm{RI}_{\text {lit }}-$ Kovats retention indices; $\mathrm{RI}_{\exp }-\mathrm{values}$ for retention indices on the HP-5 column; tr-contents $<0.05 \%$.

\begin{tabular}{|c|c|c|c|c|c|}
\hline \multirow{2}{*}{$\mathrm{RI}_{\text {lit }}$} & \multirow{2}{*}{$\mathbf{R I}_{\text {exp }}$} & \multirow{2}{*}{ Compound } & \multicolumn{3}{|c|}{ Contribution to Essential Oil (\% m/m) } \\
\hline & & & Anise & Dill & Fennel \\
\hline & & Monoterpene hydrocarbons & 0.61 & 45.50 & 4.12 \\
\hline 921 & 919 & Tricyclene & - & 0.13 & - \\
\hline 924 & 924 & $\alpha$-Thujene & 0.61 & 0.44 & - \\
\hline 932 & 924 & $\alpha$-Pinene & - & - & 1.53 \\
\hline 946 & 938 & Camphene & - & - & 0.16 \\
\hline 969 & 965 & Sabinene & - & - & $\operatorname{tr}$ \\
\hline 974 & 967 & $\beta$-Pinene & - & - & 0.13 \\
\hline 988 & 986 & $\beta$-Myrcene & - & 0.51 & $\operatorname{tr}$ \\
\hline 1002 & 996 & $\alpha$-Phellandrene & - & 13.12 & 0.38 \\
\hline 1008 & 1003 & $\delta$-3-Carene & - & - & $\operatorname{tr}$ \\
\hline 1020 & 1018 & $p$-Cymene & - & 2.26 & 0.28 \\
\hline 1024 & 1021 & Limonene & - & 29.04 & 1.32 \\
\hline \multirow[t]{2}{*}{1054} & 1052 & $\gamma$-Terpinene & - & - & 0.32 \\
\hline & & Oxygenated monoterpenes & 4.75 & 52.79 & 26.38 \\
\hline 1026 & 1024 & 1,8-cineole & 2.35 & - & 0.17 \\
\hline 1083 & 1080 & Fenchone & - & - & 25.56 \\
\hline 1095 & 1097 & Linalool & 0.43 & - & - \\
\hline 1141 & 1135 & Camphor & - & - & 0.65 \\
\hline 1148 & 1146 & Menthone & - & 0.42 & - \\
\hline 1158 & 1156 & iso-Menthone & - & 0.17 & - \\
\hline 1161 & 1166 & neo-Menthol & - & 0.28 & - \\
\hline 1174 & 1172 & Terpinen-4-ol & 0.05 & - & - \\
\hline 1184 & 1176 & Dill ether & - & 6.52 & - \\
\hline 1186 & 1185 & $\alpha$-Terpineol & 0.22 & - & - \\
\hline 1191 & 1189 & cis-Dihydrocarvone & - & 1.52 & - \\
\hline 1200 & 1196 & trans-Dihydrocarvone & - & 0.81 & - \\
\hline 1212 & 1210 & iso-Dihydrocarveol & - & 0.14 & - \\
\hline 1226 & 1223 & neoiso-Dihydrocarveol & - & 0.46 & - \\
\hline 1239 & 1238 & Carvone & - & 42.47 & - \\
\hline \multirow[t]{2}{*}{1380} & 1388 & Anisyl methyl ketone & 1.70 & - & - \\
\hline & & Phenylpropanoids & 92.91 & 0.00 & 69.28 \\
\hline 1195 & 1193 & Methyl chavicol (estragole) & 5.32 & - & 3.44 \\
\hline 1249 & 1248 & cis-Anethol & 0.11 & - & 0.79 \\
\hline \multirow[t]{2}{*}{1282} & 1280 & trans-Anethol & 87.48 & - & 65.05 \\
\hline & & Sesquiterpene hydrocarbons & 1.41 & 0.24 & 0 \\
\hline 1374 & 1366 & $\alpha$-Copaene & $\operatorname{tr}$ & - & - \\
\hline 1400 & 1397 & $\beta$-Longipinene & 0.10 & - & - \\
\hline 1471 & 1470 & Dauca-5,8-diene & - & 0.24 & - \\
\hline \multirow[t]{2}{*}{1500} & 1480 & $\gamma$-Himachalene & 1.31 & - & - \\
\hline & & Total identified & 99.68 & 98.53 & 99.78 \\
\hline
\end{tabular}

\subsection{Antifeeding Activity of EOs}

Two-way ANOVA revealed significant effects of an applied botanical type (EOs and neem), concentration and their interaction on variation of absolute deterrence coefficient (ADC) (Figure 1A). It can be noticed that the most deterrent is anise seed EO which had the higher values of ADC than other oils and neem at all tested concentrations. The value of ADC gradually increased with concentration of anise and fennel EOs and the highest deterrence was obtained at the concentration of $1 \%$ (Tukey post hoc test for factor Conc, 0.1 vs. $0.5 \%: p=0.003 ; 0.1$ vs. $1 \%$ and 0.5 vs. $1 \%: p<0.001)$. Significant Bot $\times$ Conc interaction indicated that GML sensitivity to increasing concentration differed among 
EOs and neem (Figure 1A). Namely, the slope of increase in antifeeding activity with concentration was the steepest in anise EO and the most flattened in dill EO and neem.

Antifeeding activity of the EOs was also confirmed in the choice assay. Variation in applied botanical type and in their concentration showed a significant impact on the relative deterrence coefficient (RDC) (ANOVA results in Figure 1B). Anise and dill EOs deterred larvae more effectively than neem at concentration of $0.5 \%$. With increase in EOs and neem concentration, values of RDC changed from negative values at the lowest concentration to positive values at higher concentrations. Negative mean values of RDC recorded in experimental groups where one leaf disc was treated with $0.1 \%$ solution of dill and fennel EOs, and $0.1 \%$ and $0.5 \%$ solution of neem and $0.5 \%$ solution of neem pointed to attraction activity.

The sum of an absolute and a relative coefficient (Tot coefficient), showed the best antifeeding activity in anise seed oil (Figure 1C). Concentration of $1 \%$ anise EO possessed good antifeeding activity ( $\mathrm{Tot}=119.26$ ), whereas $0.5 \%$ and $0.1 \%$ solutions were average $($ Tot $=79.54)$ and weak $($ Tot $=38.54)$ antifeedants respectively. Average activity was also recorded for $1 \%$ fennel $\mathrm{EO}$ ( $\mathrm{Tot}=77.68), 0.5$ and $1 \%$ dill $\mathrm{EO}$ (Tot $=59.18$ and 56.12 respectively), and $1 \%$ neem (Tot $=57.52)$. In other experimental groups, Tot values ranged from 10.68 to 38.19 showing weak antifeeding activity.

\subsection{Digestive Toxicity and Molting Delay Effects of EOs}

The effect of three EOs and a neem standard incorporated into the diet on larval mortality and molting was estimated after $120 \mathrm{~h}$ ( $24 \mathrm{~h}$ of exposure to EOs or neem followed by $96 \mathrm{~h}$ of feeding on control diet). As revealed by two-way ANOVA (Figure 2A) the percentage of larval mortality was significantly affected by the botanical type, as well as by the applied concentration. Comparing to neem higher toxicity was recorded in larvae fed on anise, dill, and fennel EO supplemented diets at concentrations equal or higher than $0.25 \%$. It was also noticeable that an increase in EO concentration led to significant increase in larval mortality (Figure 2A). The significant interaction term in two-way ANOVA pointed to significantly steeper slope of mortality increase with concentration in larvae exposed to EOs than to neem. At the highest concentration (1\%) dill EO was shown to be the most effective insecticide.

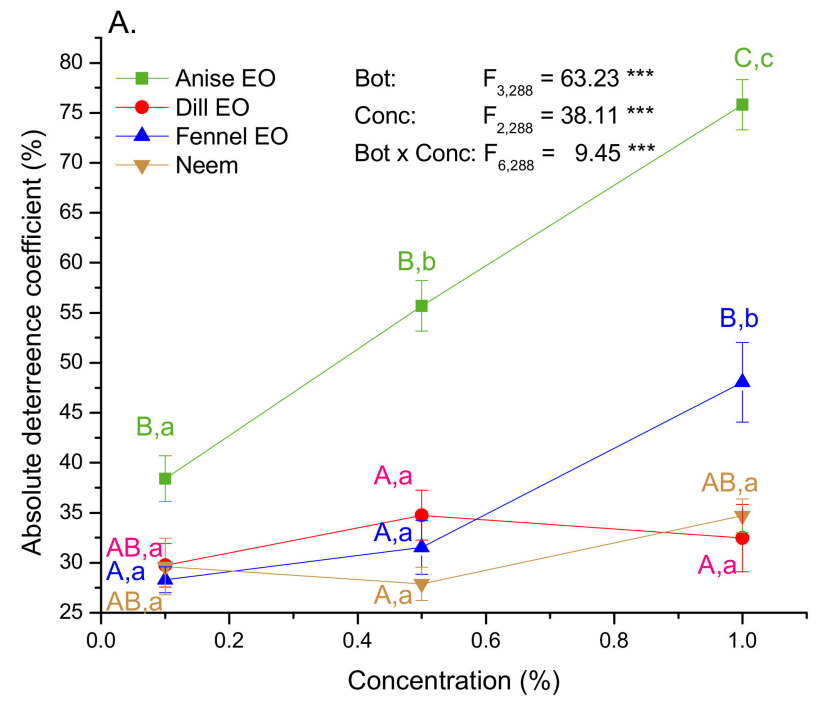

Figure 1. Cont. 

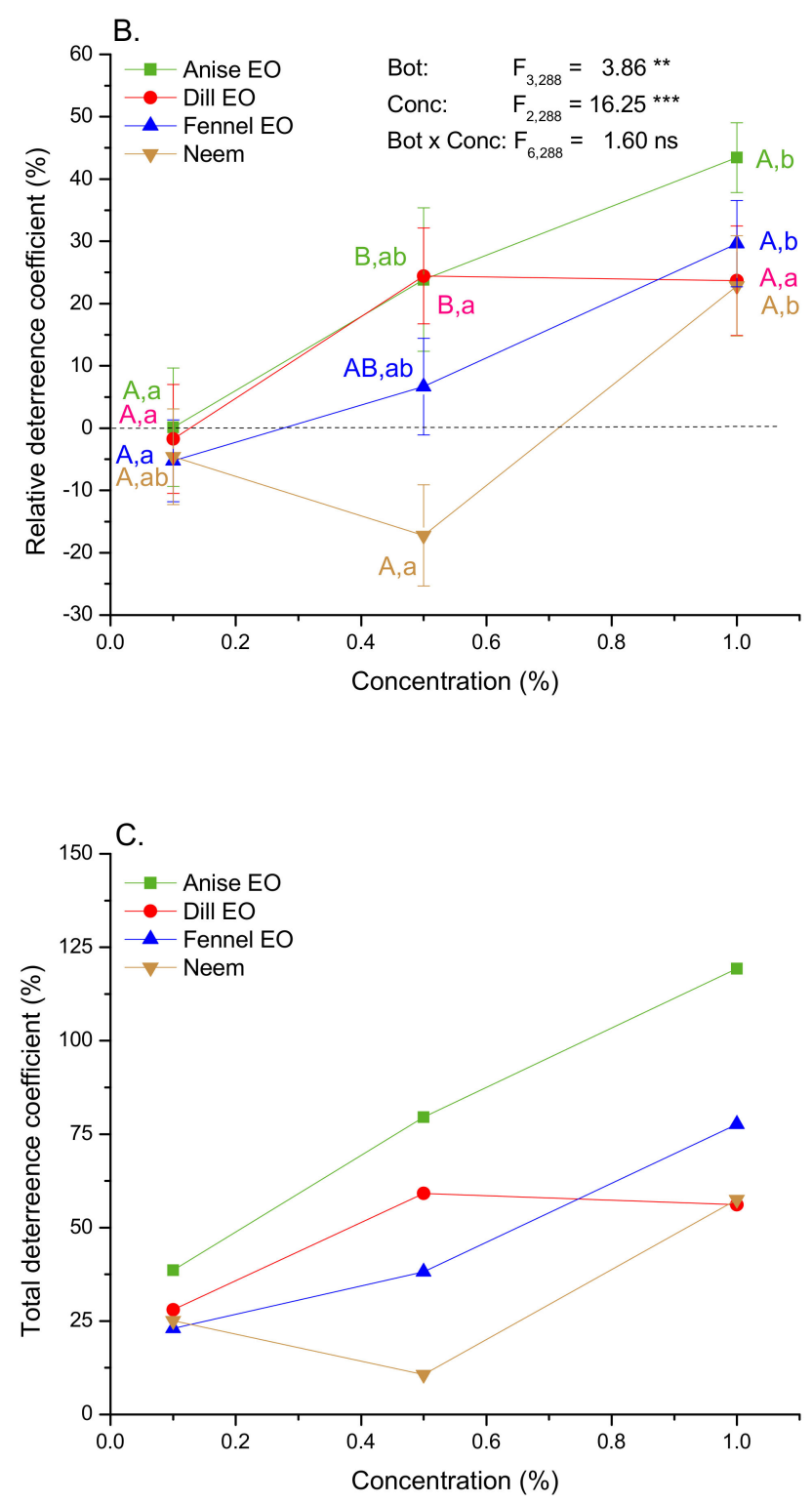

Figure 1. Absolute (A), relative (B) and total (C) deterrence coefficient (mean $\pm \mathrm{SE}$ ) in the 2nd instar GML. F-values were obtained from two-way ANOVA testing significance of the main (botanical type-Bot and concentration-Conc) and interaction (Bot $\times$ Conc) effects on analyzed traits ${ }^{* *} p<0.01,{ }^{* * *} p<0.001$ ). Different colored letters mark significant differences among EOs and neem within each concentration (capital letters A, B, C), and among concentrations within each $\mathrm{EO}$ and neem (small letters $a, b, c)$ (LSM contrasts, $p<0.05$ ).

Larval molting into the 3rd instar was also significantly affected by the botanical type and its concentrations (ANOVA results in Figure 2B). Neem appeared to be the most effective insect growth regulator as it produced significantly the highest effect on larval molting at all tested concentrations. After $120 \mathrm{~h}$, the majority of GML (98 $\pm 2 \%)$ was molted into the 3rd instar in the control group fed on untreated diet. Molting reducing effect of EOs and neem increased with concentration. Essential oils of anise and dill seed significantly reduced the percentage of larval molting at the concentration of $0.5 \%$ (about $78 \%$ reduction) which was similar to the effects of 0.05 and $0.1 \%$ neem that provoked 77 and $87 \%$ of reduction respectively. The highest concentration of $1 \%$ of either agent totally ceased the molting into the 3rd instar within the examined period of $120 \mathrm{~h}$. 

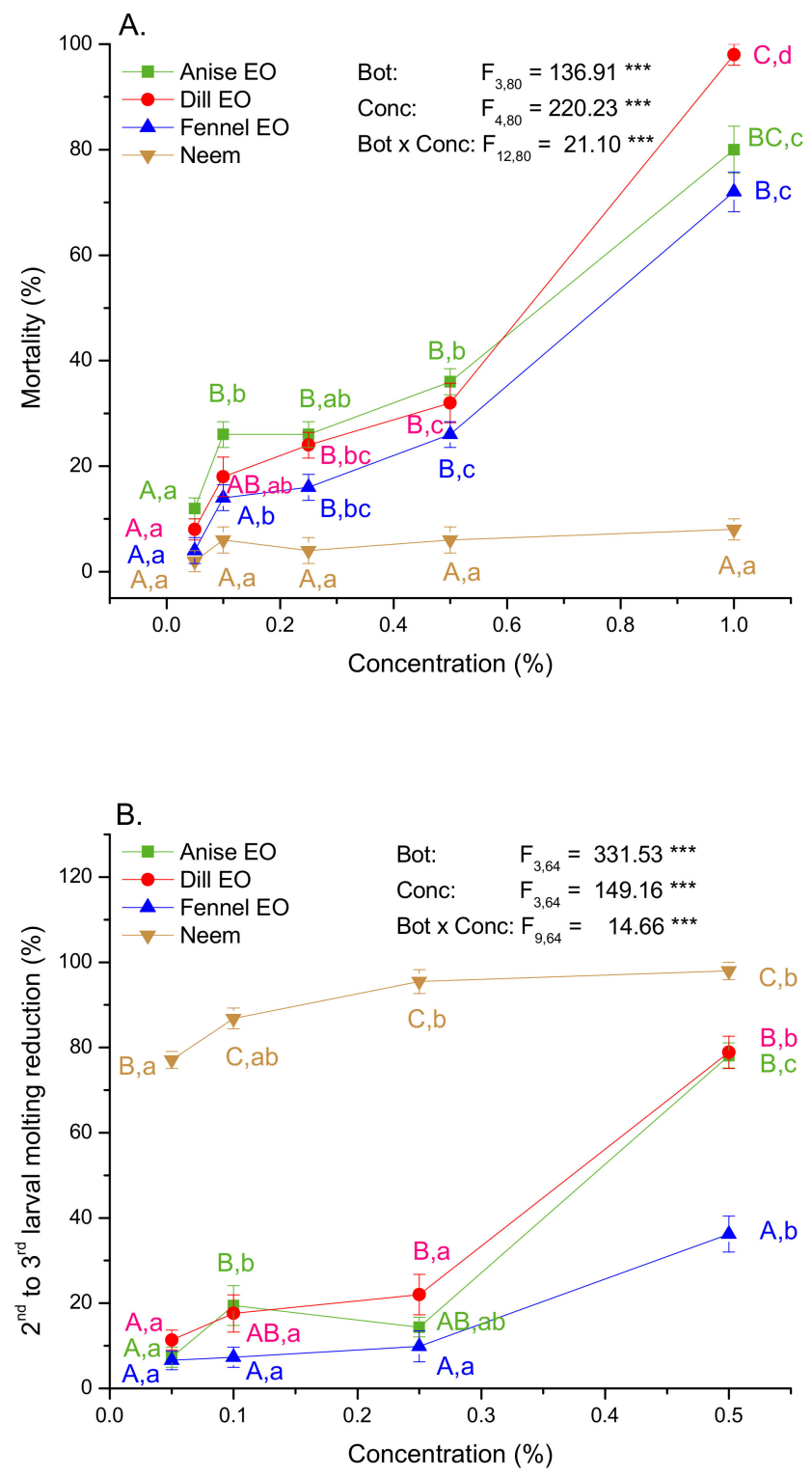

Figure 2. Digestive toxicity in the 2nd instar GML (A) and the 2nd to 3rd molting reduction (B) (mean \pm SE) after $120 \mathrm{~h}$ (24 h exposure to EOs or neem supplemented diet followed by $96 \mathrm{~h}$ feeding on untreated diet). GML were exposed to different EOs and neem concentrations. F-values were obtained from two-way ANOVA testing significance of the main (botanical type-Bot and concentration-Conc) and interaction (Bot $\times$ Conc) effects on analyzed traits $\left.{ }^{* * *} p<0.001\right)$. Different colored letters mark significant differences among EOs and neem within each concentration (capital letters A, B, C), and among concentrations within each EO and neem (small letters a, b, c, d) (LSM contrasts, $p<0.05$ ). There was no mortality in GML fed on untreated diet for $120 \mathrm{~h}$.

\subsection{Impact of EOs and Neem on Mass Gain and Amounts of Consumed, Assimilated, and Metabolized Food}

In all treatment groups mass gain was more than $75 \%$ lower comparing to the control group (Figure 3A; one-way Welch ANOVA: $\mathrm{F}_{12,43.05}=29.293, p<0.001$ ). Larvae exposed to EOs and neem ate $35-74 \%$ less food (Figure 3B, one-way ANOVA, $\mathrm{F}_{12,113}=14.77, p<0.001$ ) and showed $40-82 \%$ reduction in the amount of assimilated (Figure $3 \mathrm{C}, \mathrm{F}_{12,113}=18.83, p<0.001$ ) and $24-67 \%$ reduction in the amount of metabolized food (Figure $3 \mathrm{D}, \mathrm{F}_{12,113}=6.74, p<0.001$ ). Differences of treatment groups from the control group were mostly highly significant (Tables S1 and S2). 

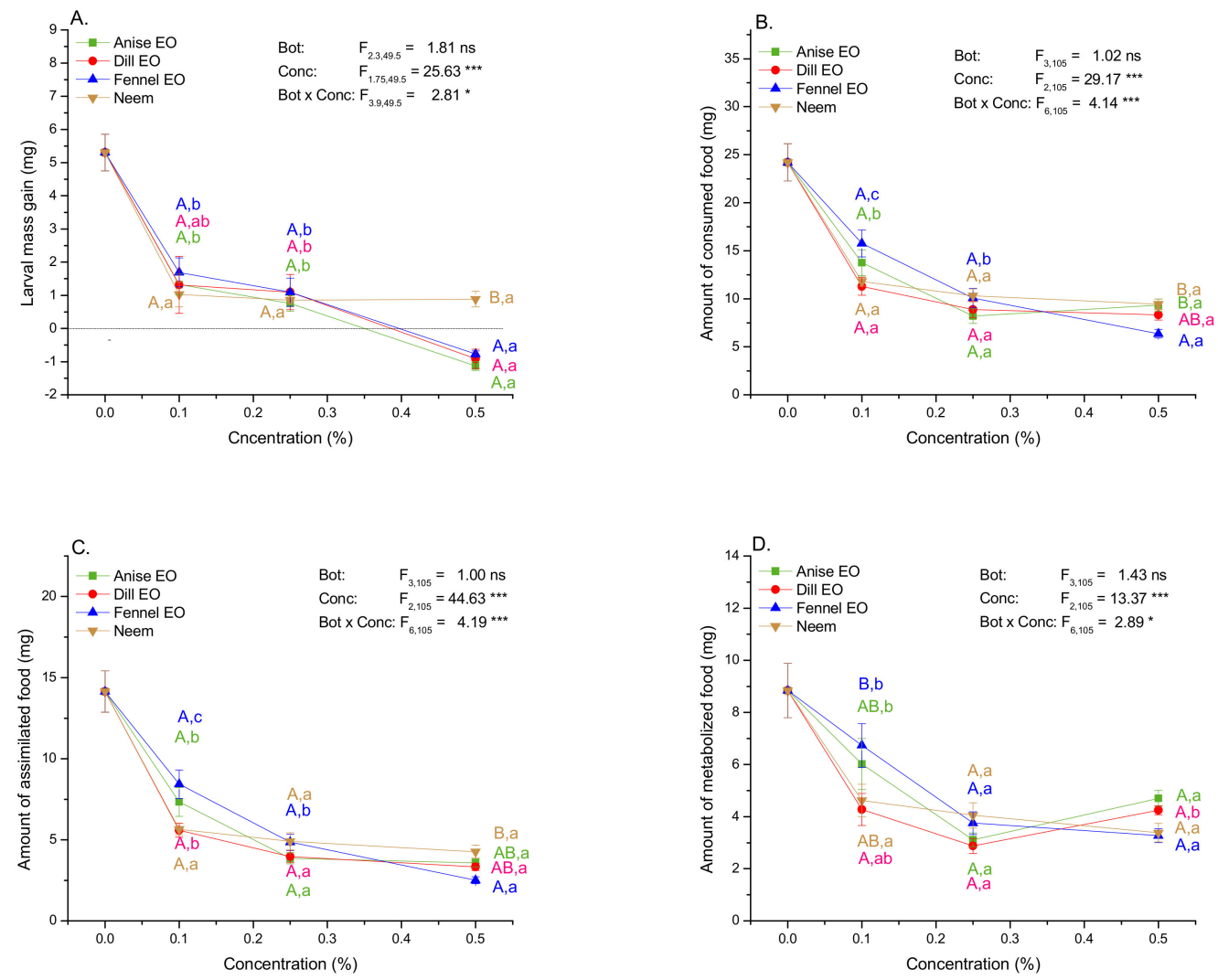

Figure 3. Mass gain (A) and amounts of consumed (B), assimilated (C) and metabolized food (D) (mean \pm SE) in the 4th instar GML depending on the botanical type (Bot) (anise, dill and fennel EOs, commercial neem-based insecticide) and concentration (Conc). F-values indicate significance of the effects of Bot, Conc and interaction terms in two-way ANOVA $\left({ }^{*} p<0.05,{ }^{* * *} p<0.001\right)$. Significant differences among specific experimental groups are presented by different capital colored letters A, B (EO and neem comparisons within each concentration) and small letters $\mathrm{a}, \mathrm{b}$ (comparisons among concentrations within each EO and neem) (LSM contrasts, $p<0.05$ ).

On average, across all concentrations, EOs and neem were equally effective over these traits (Figure 3; nonsignificant Bot term in two-way ANOVAs). Negative impact became more expressed at high concentrations (significant Conc term) and it was the most apparent in larvae exposed to fennel EO. Larvae of the Neem group did not show significant change of traits with concentration increase (Figure 3; significant Bot $\times$ Conc term). In difference to neem group, larvae of the groups fed on $0.5 \%$ EOs lost their mass. In addition, larvae of the $0.5 \%$ fennel EO group larvae consumed and assimilated significantly less food.

\subsection{Impact of EOs and Neem on Growth and Nutritional Indices}

Similar to the results of mass gain and total consumption, larval growth relative to initial mass (RGR) showed negative values and food consumption relative to initial mass (RCR) had the lowest values at 0.5\% EO (Figure 4A,B). RGR (one-way Welch ANOVA, $\left.\mathrm{F}_{12,43.009}=31.34, p<0.001\right)$ and $\mathrm{RCR}\left(\mathrm{F}_{12,43.068}=15.76, p<0.001\right)$ differed significantly among experimental groups and exposure to $0.1,0.25$ and $0.5 \%$ concentration of EOs and neem led to significantly lower RGR (70-119\% reduction) and RCR (42-67\% reduction) values comparing to the control group (Table S2). Besides primary feeding deterrence reflected in reduced RCR, GML mostly exhibited post-ingestion toxic effects of EOs and neem as they allocate less ingested resources towards growth. In the food, EOs provoked $54-157 \%$ lower ECI values comparing to the control $\left(\mathrm{F}_{12,42.438}=30.20, p<0.001\right)$. Only 0.1 and $0.25 \%$ dill EO and $0.25 \%$ fennel EO acted mainly as feeding deterrents (Table S2). 

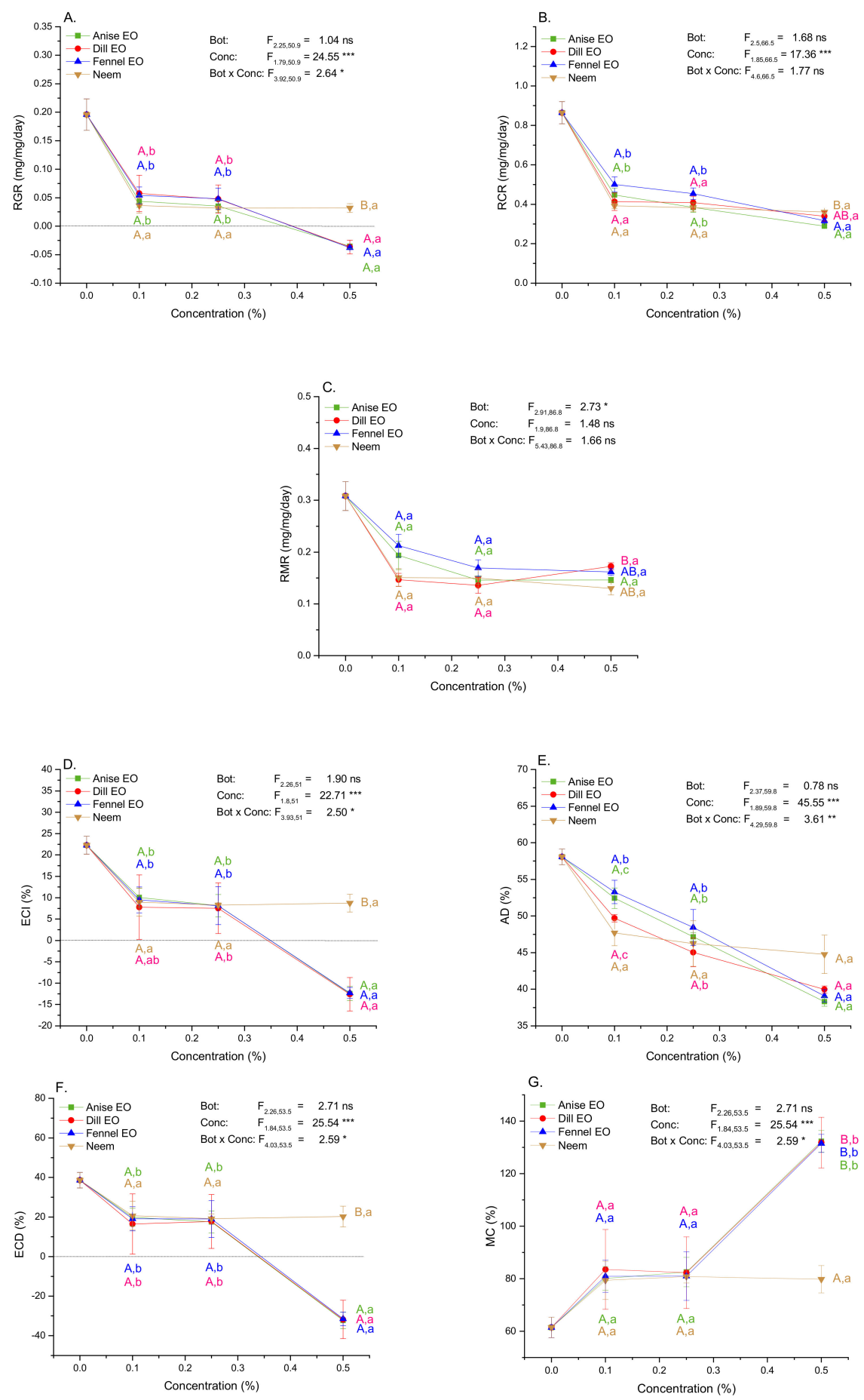

Figure 4. Nutritional indices (mean $\pm \mathrm{SE}$ ) in 4th instar gypsy moth larvae after $48 \mathrm{~h}$ of feeding on control and diet treated with EOs or neem. RGR-relative growth rate (A); RCR-relative consumption rate (B); RMR-relative metabolic rate (C); ECI-efficiency of conversion of ingested food (D); AD-approximate digestibility (E); ECD-efficiency of conversion of digested food (F); $\mathrm{MC}$ - metabolic cost (G). F-values obtained by nonparametric two-way ANOVA indicate significance of the main and interaction effects of botanical type (Bot) (anise, dill, and fennel EOs and commercial neem-based insecticide) and concentration (Conc) $\left({ }^{*} p<0.05,{ }^{* *} p<0.01,{ }^{* * *} p<0.001\right)$. Significant differences among specific experimental groups are presented by different large colored letters A, B (EO and neem comparisons within each concentration) and small letters $\mathrm{a}, \mathrm{b}$ (comparisons among concentrations within each EO and neem) (LSM contrasts, $p<0.05$ ). 
Decreased ECI can be a consequence of a lower proportion of assimilated relative to consumed food (AD) and/or a lower proportion of assimilated food allocated towards growth (ECD). EOs and neem treatments significantly affected both indices (one-way Welch ANOVA, AD: $\mathrm{F}_{12,43.642}=41.37, p<0.001 ; \mathrm{ECD}: \mathrm{F}_{12,43.45}=24.97, p<0.001$ ) leading to $8-34 \%$ and $47-184 \%$ reduction respectively. However, whereas AD was significantly reduced in the majority of EO treated groups, ECD showed significant change only at the highest EO concentration (Figure 4; Table S2). Processing food that contains $0.5 \%$ EO impose a high metabolic cost to gypsy moth larvae which exceeded the value of $100 \%$ (Figure $4 \mathrm{G}$ ). The proportion of metabolized food relative to initial larval mass (RMR) was reduced by $31-58 \%\left(\mathrm{~F}_{12,43.454}=4.01, p<0.001\right)$ which was most probably caused by a significant decrease in the amount of assimilated food. It can be noticed from Table S2 that RMR and $\mathrm{AD}$ values are significantly lower comparing to the control.

At two lowest concentrations $(0.1 \%$ and $0.25 \%)$ EOs and neem did not differ in the impact on nutritional indices (Figure 4; nonsignificant Bot term in two-way ANOVA). Except for RMR, all indices were strongly dependent on concentration (Figure 4; significant Conc term in two-way ANOVA). Concentration-dependent decrease in RGR (Figure 4A), ECI (Figure 4D), AD (Figure 4E), ECD (Figure 4F), and increase in MC (Figure 4G) was steeper in EOs than neem treated groups (significant Bot $\times$ Conc term in two-way ANOVA). Comparisons of EOs impacts with the impact of neem standard at the concentration of $0.5 \%$ revealed that EOs were more effective in reducing RGR, ECI and ECD (Figure 4A,D,F). Additionally, anise and fennel EOs were more effective in reducing RCR (Figure 4B).

\section{Discussion}

The impact of essential oils on behavior, survival, and reproduction of various pest insects has been widely studied $[61,64,65]$. Relative effects of EOs are trait- and sex-specific, and depend on insect species, developmental stage, oil composition, mode of application, EO concentration and time of exposure [43,47,66-69]. Already recognized as potential green pesticides, EOs also proved to be promising for the management of tree pests [70-73]. In the present work, we demonstrated that EOs from three Apiaceae species (anise, dill and fennel) had significant biological activity affecting various GML traits.

\subsection{Apiaceae EOs Are Toxic, Deter Feeding and Delay Molting in GML}

Anise and dill seed EOs appeared to be the most effective agents against 2nd instar GML since anise EO had good antifeeding activity and both EOs induced high mortality and delayed larval molting. Kostić et al. [63] found strong antifeeding activity of Athamantha haynaldii and Myristica fragrans Houtt. EOs. At concentration of $0.1 \%$ these EOs showed two times higher absolute deterrence coefficient than anise EO. Additionally, Tanacetum vulgare L. EO delayed molting more effectively than Apiaceae EOs in our study [74]. On the other hand, digestive toxicity and antifeeding activity of Apiaceae EOs obtained in no-choice assays were higher comparing to Ocimum basilicum L. and T. vulgare EOs, and oil-in-water EO emulsions from Thymus herba-barona Loisel. and Rosmarinus officinalis L. [70,74-76]. The antifeeding activity of anise EO is similar to that of ethanolic leaf extracts of Aesculus hyppocastanum L. and Morus alba L. [77].

Our findings are in accordance with toxic, antifeeding, and molting delay effects of Apiaceae EOs described in other insect species. Anise, dill and fennel EOs had good larvicidal, repellent, and antifeeding effects on lepidopteran pests [43,47,78-80]. Comparisons of biological activities of anise, dill and fennel EOs revealed that relative activity depended on insect species. For example, similar to our results, dill EO is better toxicant than fennel EO in Pseudaletia unipuncta Haworth [81] and better toxicant than anise EO in Musca domestica L. larvae [82]. In contrast, fennel is more effective than dill in larvae of Spodoptera littoralis Boisduval [83] and more effective than anise in Tribolium castaneum Herbst [84]. Regarding antifeeding effects of EOs and EO compounds, many studies revealed higher deterrence in choice than no-choice assays [85-87]. Since we obtained higher values of the absolute 
than the relative deterrence coefficient, the antifeedant activity of anise, dill and fennel EOs might be more based on the post-ingestive toxicity than on their antifeeding activity.

Comparisons of biological activity of anise, dill and fennel EOs with commercial insecticide neem revealed higher toxicity and antifeeding activity of EOs, and stronger molting delay effects of neem. It has been proved that the neem dominant component azadirachtin is very effective to inhibit the synthesis of active molting hormone 20-hydroxyecdysone, disrupts growth, may lead to incomplete ecdysis, malformations in pupae and adults and reduced fecundity [88]. EOs may also act as growth regulators and prolong the development of insect immature stages [89-91]. It has been suggested that components of n-butanol extracts from fruit of Apiaceae plant Ammi visnaga L. may inhibit ecdysone and further affect the activity of acid phosphatases and molting of Schistocerca gregaria Forsskål nymphs [92].

\subsection{EO Composition Might Account for Differences in Their Biological Activity}

We showed that EOs of anise and fennel were rich in phenylpropanoid trans-anethol and dill $\mathrm{EO}$ was rich in oxygenated monoterpene carvone and monoterpene hydrocarbons $\alpha$-phellandrene and limonene. High toxicity and antifeeding activity in insect pests are induced by major compounds of anise, dill and fennel EOs: trans-anethol [93-95] and carvone [53,96-98]. It has been suggested that oxygenated compounds provide higher insecticidal activity than monoterpene hydrocarbons [99]. For example, the presence of phenylpropanoids in EOs is a significant variable determining their toxicity against $T$. castaneum [84]. In Spodoptera frugiperda J.E. Smith they might be involved in delayed pupation through inhibition of tyrosinase and cuticle synthesis [100,101]. However, according to our results, the most toxic to 2nd instar GML was dill $\mathrm{EO}$ which comparing to anise and fennel EOs contained less oxygenated compounds and more monoterpene hydrocarbons. Studies on the structure-function relationship of EO constituents point out that molecular shape, degree of saturation, volatility and type of functional groups contribute to the efficacy of natural insecticides [102]. Besides, it has been well documented that EO compounds act in synergy and affect multiple targets in pest insects [93,94,103-105].

Physiological mechanisms of insecticidal activity of EOs, their compounds and/or a mixture of compounds is to act as neurotoxins and lead to the paralysis and death of insect pests through the inhibition of acetylcholine esterase (AChE), as well as through blockage of octopamine receptors and/or interference with GABA-gated sodium channels [64]. For example, anise and fennel EOs as well as their constituents, anethol, phellandrene, limonene, fenchone, carvon, and estragol inhibit AChE, carvon intensify GABA-induced Clcurrent whereas limonene acts through the octopaminergic system [84,106-109]. Modulation of the GABA-ergic system by plant secondary metabolites is related to their antifeeding activity in pest insects [110-112]. Besides modulation of odor and gustatory receptors, the antifeeding activity of EOs can be also an indirect consequence of induced toxicity due to disrupted structure of midgut peritrophic membrane and epithelium, oxidative damages to macromolecules, and inhibition of digestive and detoxification enzymes $[44,47,113,114]$.

\subsection{Apiaceae EOs Reduce GML Growth through Pre- and Post-Ingestive Mechanisms}

Obviously, exposure to EOs and EOs compounds induce numerous changes in physiological processes that may further affect pest insect behavior and life-history traits. In the present paper, we assessed how three Apiaceae EOs affected the growth and nutritional indices of GML. We showed mainly significant adverse effects of EOs and neem on GML growth (RGR), consumption (RCR), assimilation (AD) and metabolism (RMR, ECI, ECD, $\mathrm{MC}$ ). In difference to neem experimental group, larvae fed on $0.5 \%$ EO supplemented diet lost their mass and had negative values of growth and gross/net growth efficiencies (RGR, ECI, ECD). Therefore, GML mass change during 2 days of feeding was provoked not only by among-treatment variation in the amount of consumed and assimilated food (pre-ingestive and pre-digestive mechanisms, respectively) but also was a consequence of the EO influence on post-ingestive and post-digestive mechanisms. Our results are in 
accordance with findings of other studies which showed negative values of RGR and ECI in T. castaneum adults exposed to anise EO [45] and 4th instar P. unipuncta larvae exposed to trans-anethol [55].

Reduced consumption obtained in the present paper in 2nd and 4th instars fed on anise, dill and fennel EO treated diets as well as in studies on the effects of other EOs on GML $[63,70,74,75]$ pointed to the sensitivity of this species to the presence of antifeedants in EOs. Many papers also confirmed the antifeedant activity of terpenes and terpenoids in GML $[49,115,116]$. Comparing to tansy EO [74], Apiaceae EOs appeared to be more effective in reducing GML growth and consumption. Tansy EO did not induce mass loss and negative values of ECI and ECD, consumption was decreased by $38 \%$ compared to $63-67 \%$ reduction in response to Apiaceae EOs. In addition, AD was not affected by tansy EO whereas $31-34 \%$ and $23 \%$ reduction was recorded on Apiaceae EOs and neem respectively. EOs [44,114] and azadirachtin [117-120] disrupted gut structures and thus inhibited digestive enzyme activities and impaired nutrient absorption which might account for the observed decrease in ECI and AD.

Our results showed that RMR decreased along with a decrease in RCR. Such response depended on concentration so that RMR and RCR were not significantly changed at the lowest concentration of anise and fennel EOs. Likewise, extracts of Inula racemosa Hook which contained sesquiterpene lactones did not affect RCR and RMR of Spodoptera litura Fabricius larvae at the lowest examined concentration, whereas both indices were reduced at the highest concentration [121]. Sousa et al. [65] recorded a significant reduction in RMR in P. unipuncta exposed to trans-anethol and EO from Petroselinum crispum (Mill.) Nyman ex A.W. Hill, two botanicals which induced larval mass loss. Despite the decrease in the amount of metabolized food in GML fed on EO- and neem-supplemented diets, its proportion relative to ingested and assimilated food increased leading to lower ECI and ECD values.

Reduction in food utilization efficiency by botanical treatments points to their chronic toxicity which forces larvae to reallocate energy resources from growth to defense. Depletion of metabolites and adaptive increase in antioxidative and detoxification enzymes have been described in pest insects exposed to EOs [114,122-126] and azadirachtin [127,128]. Similar results were obtained in studies dealing with the impact of Apiaceae EOs on insect pests [45,113,129-131]. In lepidopteran pests, S. frugiperda and Anticarsia gemmatalis Hübner limonene, carvon, estragol and anethol (compounds of anise, dill and fennel seed EOs) are detoxified by microsomal cytochrome P-450 monooxygenases [132]. This enzyme is also elevated in GML fed on terpene-rich plants [133].

\section{Materials and Methods}

\subsection{Plant Material and EOs Isolation}

Tested EOs have been extracted from seeds of anise (Pimpinella anisum L.), dill (Anethum graveolens L.), and fennel (Foeniculum vulgare Mill.) cultivated on the experimental fields of the Institute for Medicinal Plant Research "Dr. Josif Pančić" in Pančevo, Serbia $\left(44^{\circ} 52^{\prime} 14^{\prime \prime} \mathrm{N}\right.$; $20^{\circ} 38^{\prime} 42.7164^{\prime \prime}$ E, altitude $81 \mathrm{~m}$ ). EOs were obtained by hydrodistillation of their seeds using a Clevenger-type apparatus [134].

\subsection{Chemical Characterization of EOs}

The essential oils samples were diluted in ethanol $\left(10 \mu \mathrm{L} \mathrm{mL}{ }^{-1}\right)$ and $1 \mu \mathrm{L}$ of each solution was injected in a split-mode (1:30). Gas chromatography was performed using the GC Agilent Technologies 7890A apparatus equipped with a split-splitless injector attached to an HP-5 column $(30 \mathrm{~m} \times 0.32 \mathrm{~mm}$, film thickness $0.25 \mu \mathrm{m})$ and fitted to a flameionization detector (FID). The operating conditions were: the carrier gas was $\mathrm{H} 2\left(1 \mathrm{~mL} / \mathrm{min} / 210{ }^{\circ} \mathrm{C}\right)$; the temperatures were set as follows: injector at $250{ }^{\circ} \mathrm{C}$ and detector at $280{ }^{\circ} \mathrm{C}$, while the column temperature was linearly programmed from 40 to $260{ }^{\circ} \mathrm{C}$ at $4{ }^{\circ} \mathrm{C} / \mathrm{min}$. The percentage composition was computed from the peak areas, without correction factors. 
The Gas Chromatography-Mass Spectrometry was performed using the HPG $1800 \mathrm{C}$ Series II GCD analytical system equipped with an HP-5MS column (30 m $\times 0.25 \mathrm{~mm}$, film thickness $0.25 \mathrm{~m})$. The carrier gas was He $(1 \mathrm{~mL} / \mathrm{min})$. Other chromatographic conditions were the same as those for Gas Chromatography with Flame-Ionization Detection. The transfer line was heated at $260{ }^{\circ} \mathrm{C}$. The mass spectra were recorded in the EI mode $(70 \mathrm{eV})$ in the range of $m / z 40-450$. The identification of individual constituents was accomplished by comparing their spectra to those available from MS libraries (NIST/Wiley) and by comparing their experimentally determined retention indices (calibrated AMDIS) to the data from the literature [135].

\subsection{GML Rearing}

Gypsy moth egg masses were collected from natural populations in the Lipovica Forest, near Belgrade, Serbia ( $44^{\circ} 38^{\prime} 34^{\prime \prime} \mathrm{N} ; 20^{\circ} 26^{\prime} 13^{\prime \prime}$ E, altitude $270 \mathrm{~m}$ ) during the autumn. Egg masses were maintained at $4{ }^{\circ} \mathrm{C}$ until the next spring. Eggs were mechanically cleaned of hairs, disinfected by soaking into $0.1 \%$ sodium hypochlorite solution for $5 \mathrm{~min}$, washed with distilled water for $10 \mathrm{~min}$ and air-dried [136]. Eggs from the middle parts of 25 egg masses (100 eggs per egg mass, 2500 eggs in total) were mixed and put into flasks for hatching in a SANYO microclimate chamber at $25 \pm 1{ }^{\circ} \mathrm{C}, 65 \pm 5 \%$ relative humidity and neon diffuse light of 30159.29 candelas with a 15:9 L:D photoperiod. Newly hatched larvae were transferred to Petri dishes $(90 \times 14 \mathrm{~mm})$ at a density of ten 1 st instar larvae per dish and fed with an artificial gypsy moth diet (MP Biomedicals, Inc., Irvine, CA, USA, cat. no. 296029304).

\subsection{Antifeeding Activity}

The antifeeding activity was assessed in the 2nd instar larvae by no-choice and choice tests. After the molting into the 2 nd instar, larvae were starved for $24 \mathrm{~h}$. An agar-water (2\%) layer of $2 \mathrm{~mm}$ thickness was poured into Petri dishes $(90 \times 14 \mathrm{~mm})$. After agar turned solid we covered it with wet filter paper and placed one oak (Quercus robur L.) leaf disc (30 mm diameter) in the center of the Petri dish in the no-choice test or two discs on opposite sides of the Petri dish in the choice test. Leaf disc treatments were performed by the leaf dipping method [137]. Namely, discs were immersed either in 50\% ethanolic solution of EOs or $\mathrm{NeemAzal}^{\circledR}$-T/S (Trifolio-M GmbH) at three different concentrations $(0.1,0.5$, and $1.0 \%$ ) or in a solvent for $3 \mathrm{~s}$. In the no-choice test leaf discs were treated with the EOs, neem or solvent, whereas in the choice test, one leaf disc was treated with the EOs or neem and the other with the solvent. After 30 minutes' evaporation of the solvent, leaf discs were fixed to the agar layer with pins. Then one larva was introduced into the center of each Petri dish. After $48 \mathrm{~h}$, the remains of the consumed discs were scanned at $200 \mathrm{dpi}$ in jpg format. Quantification of the consumed surface area for each leaf disc was done by subtracting remained leaf disc area from the disc area at the start of the experiment using ImageTool software 3.0 [138]. In each experimental group antifeeding activity of EOs and neem was analyzed in 25 larvae (replicates).

Based on the consumed leaf disc areas in the no-choice and choice tests, absolute $(\mathrm{ADC})$, relative (RDC), and total (Tot) deterrence coefficients were calculated according to the formulas of $[85,139]$ :

$$
\begin{gathered}
\mathrm{ADC}=(\mathrm{CC}-\mathrm{TT}) /(\mathrm{CC}+\mathrm{TT}) \times 100 \\
\mathrm{RDC}=(\mathrm{C}-\mathrm{T}) /(\mathrm{C}+\mathrm{T}) \times 100 \\
\text { Tot }=\mathrm{A}+\mathrm{R}
\end{gathered}
$$

where CC is the mean consumed surface area for GML from the control group and TT is the consumed surface area of the leaf discs treated with EOs or neem in the no-choice test; $\mathrm{C}$ is the consumed surface area of the control leaf disc and $\mathrm{T}$ is the consumed surface area of the treated leaf disc in the choice test. 
The total deterrence coefficient can range from -200 to +200 . According to Tot values EOs can be ranged as very good (Tot values from 151 to 200), good (101-150), average $(51-100)$, and weak deterrents $(<50)$. Negative Tot values suggest attractant properties of EOs.

\subsection{Digestive Toxicity and Molting}

In the digestive toxicity test, EOs and neem were incorporated into the artificial diet at different concentrations ( 0 - control group, $0.05,0.1,0.25,0.5$, and $1 \%$ ). After starvation for $24 \mathrm{~h}$, ten 2 nd instar larvae were put into the Petri dishes and fed ad libitum either on control diet or on EOs and neem treated diets for $24 \mathrm{~h}$. After that, they were transferred into clean Petri dishes and fed on control diets for another $96 \mathrm{~h}$ (120 h from the beginning of exposure). During the experiment, two fresh cubes of artificial diet per Petri dish were provided daily. Within each EO or neem and their concentration five replicates were analyzed $(5 \times 10$ larvae per experimental group). Larval mortality and molting were monitored daily and $120 \mathrm{~h}$ after the beginning of experiment, the percentage of mortality and percentage of molting into the 3 rd larval instars were determined. The percentage of molting reduction relative to the control was calculated as $(\mathrm{C}-\mathrm{T}) / \mathrm{C} \times 100$ where $\mathrm{C}$ was the mean percentage of molted larvae in the control group and $\mathrm{T}$ was the percentage of molted larvae fed on $\mathrm{EO}$ or neem treated diet.

\subsection{Growth and Nutritional Indices}

After molting into the 4th larval instar, larvae were separated and exposed to $24 \mathrm{~h}$ starvation after which their mass was measured individually. Larvae were daily supplied with cubes of the artificial diet with incorporated EOs or neem. As preliminary study showed that larvae fed on EO supplemented diets decreased their mass at the concentration of $0.5 \%$, the study of $\mathrm{EO}$ and neem influence on nutritional physiology of GML encompassed concentrations of 0 (control), $0.1,0.25$, and $0.5 \%$. Cubes of artificial gypsy moth diet were weighed before and after the feeding trial, as well as the excrement was weighed at the end of the experiment. Larval mass was measured again $48 \mathrm{~h}$ after the experiment was set. All indices were estimated on a dry mass basis. Larvae, uneaten cubes and excrements were dried at $65^{\circ} \mathrm{C}$ for $72 \mathrm{~h}$. After this time, the mass of each larva, uneaten cubes, and excrements were weighed. A regression of dry on fresh mass in a random sample of 30 larvae and cubes of artificial diet per experimental group was used for estimating the dry mass of larvae and cubes of artificial diet at the beginning of the experiment. Based on these data the following indices were calculated according to the standard formulas [140-142] (Table 2).

Table 2. Formulae for calculation of growth and nutritional indices.

\begin{tabular}{ll}
\hline Indices & Formula \\
\hline Relative growth rate & $\mathrm{RGR}=\left(\mathrm{m}_{2}-\mathrm{m}_{0}\right) /\left(2 \times \mathrm{m}_{0}\right)$ \\
Relative consumption rate & $\mathrm{RCR}=\mathrm{m}_{\mathrm{c}} /\left(2 \times \mathrm{m}_{0}\right)$ \\
Relative metabolic rate & $\mathrm{RMR}=\left[\left(\mathrm{m}_{\mathrm{c}}-\mathrm{m}_{\mathrm{e}}\right)-\left(\mathrm{m}_{2}-\mathrm{m}_{0}\right)\right] /\left(2 \times \mathrm{m}_{0}\right)$ \\
The efficiency of conversion of ingested food (gross growth efficiency) & $\mathrm{ECI}=\left(\mathrm{m}_{2}-\mathrm{m}_{0}\right) / \mathrm{m}_{\mathrm{c}} \times 100$ \\
Approximate digestibility (assimilation efficiency) & $\mathrm{AD}=\left(\mathrm{m}_{\mathrm{c}}-\mathrm{m}_{\mathrm{e}}\right) / \mathrm{m}_{\mathrm{c}} \times 100$ \\
The efficiency of conversion of digested food (net growth efficiency) & $\mathrm{ECD}=\left(\mathrm{m}_{2}-\mathrm{m}_{0}\right) /\left(\mathrm{m}_{\mathrm{c}}-\mathrm{m}_{\mathrm{e}}\right) \times 100$ \\
Metabolic cost & $\mathrm{MC}=100-\mathrm{ECD}$ \\
\hline
\end{tabular}

$\mathrm{m}_{0}$-initial larval mass at the beginning of the experiment; $\mathrm{m}_{2}$-larval mass at the end of the experiment (2 days of feeding); $\left(\mathrm{m}_{2}-\mathrm{m}_{0}\right)-$ mass gain; 2-duration of the experiment expressed in days; $\mathrm{m}_{\mathrm{c}}$ - the amount of consumed food (difference between final and initial dry food mass); $\mathrm{m}_{\mathrm{e}}-\mathrm{a}$ dry mass of excrements; $\left(\mathrm{m}_{\mathrm{c}}-\mathrm{m}_{\mathrm{e}}\right)$ - the amount of assimilated food; $\left[\left(\mathrm{m}_{\mathrm{c}}-\mathrm{m}_{\mathrm{e}}\right)-\left(\mathrm{m}_{2}-\mathrm{m}_{0}\right)\right]$-the amount of metabolized food.

\subsection{Statistical Analysis}

Parametric one-way and two-way ANOVAs were performed by software package Statistica 7.0 (StatSoft, Inc., Tulsa, OK, USA) on untransformed values of the relative deterrence index and $(X+0.5)^{0.5}$ transformed values of the absolute antifeeding index, 
larval mortality, larval molting reduction, and log-transformed values of the amount of consumed food, amount of assimilated food, and amount of metabolized food. Dunnett test following one-way ANOVA was used to estimate the significance of differences of treatment groups from the control group. Two-way ANOVA was carried out to evaluate the main and interaction effects of the botanical type (EOs or neem) and the botanical concentration as fixed factors on examined traits. A least square means (LSM) test with the Bonferroni correction was used for a posteriori comparisons (contrasts) of different concentration effects within each EO and neem as well as comparisons of EOs and neem effects within each concentration.

For mass gain, and growth and nutritional indices assumption of homogeneity of variances was strongly violated (Levene's test, $p<0.0001$ ). Therefore, significant differences of treatment groups from the control group were revealed by Welch one-way ANOVAs for each pair of comparison followed by the Bonferroni correction [143]. Significance of main and interaction effects of botanical type and concentration on growth and nutrition indices were estimated by nonparametric two-way ANOVA [144]. LS means tests with Bonferroni correction was used for a posteriori comparisons.

\section{Conclusions}

In whole, Apiaceae EOs can be considered as promising strategy for gypsy moth control based on strong negative effects on survival and consumption in 2nd instar, and impairment of nutritional physiology in 4th instar larvae. Whereas anise EO was the best antifeedant, dill EO exhibited the highest mortality. At a concentration of $0.5 \%$, the three Apiaceae EOs were more effective than commercial insecticide neem in reducing RGR, ECI, $\mathrm{AD}$ and $\mathrm{ECD}$ of 4th instar GML. Anise, dill and fennel are spice plants used in human nutrition, and have low toxicity to mammals and other non-target organisms [43,103,145-148]. However, the commercialization of anise and dill EO-based insecticides necessitates further investigations to find formulations of improved $\mathrm{EO}$ solubility and persistence whose efficacy would be finally tested in the field [19].

Supplementary Materials: The following are available online at https:/ /www.mdpi.com/article/10 $.3390 /$ plants10102194/s1, Table S1: Summary of $p$-values from Dunnett test indicating significance (values in bold) of differences in amounts of consumed, assimilated and metabolized food between treatment groups and control group. Table S2: Summary of $p$-values from the Welch one-way ANOVA indicating significance (values in bold) of differences in growth and nutritional indices between treatment groups and control group. MG-mass gain; RGR - relative growth rate; RCR-relative consumption rate; RMR - relative metabolic rate; ECI - efficiency of conversion of ingested food; $\mathrm{AD}$-approximate digestibility; ECD—efficiency of conversion of digested food; MC—metabolic cost. Figure S1: Chromatograms obtained for the EOs extracted from the seeds of Apiaceae plants (anise-Pimpinella anisum, dill—Anethum graveolens, fennel—Foeniculum vulgare).

Author Contributions: Conceptualization, M.K. and S.M.; methodology, T.M., S.M. and J.L.; formal analysis, I.K., D.Š.J., J.L. and T.M.; investigation, I.K., M.K., S.M. and J.L.; resources, T.M., M.K. and S.M.; data curation, I.K., D.Š.J. and J.L.; writing-original draft preparation, D.Š.J. and J.L.; writing-review and editing, J.L., D.Š.J., I.K. and T.M.; supervision, S.M. All authors have read and agreed to the published version of the manuscript.

Funding: This research was funded by the Ministry of Education, Science and Technological Development of the Republic of Serbia, grant number 451-03-9/2021-14/200007.

Institutional Review Board Statement: The study was conducted according to the Serbian and European ethical normative (Directive 2010/63/EU) on the protection of animals used for experimental and other scientific purposes. Among invertebrates, ethical protection is granted to cephalopodes by the EU and Serbian legislatives. The national ethical legislative also grants protection to endangered species. However, Lymantria dispar does not fall into one of these categories and this study is in concordance with current state of ethical legislative in the EU and the Republic of Serbia.

Data Availability Statement: Publicly available datasets were analyzed in this study. This data can be found here: http:/ / radar.ibiss.bg.ac.rs/handle/123456789/4465, accessed on 12 October 2021. 
Conflicts of Interest: The authors declare no conflict of interest.

\section{References}

1. Liebhold, A.M.; Gottschalk, K.W.; Muzika, R.M.; Montgomery, M.E.; Young, R.; O’Day, K.; Kelley, B. Suitability of North American Tree Species to the Gypsy Moth: A Summary of Field and Laboratory Tests; U.S. Department of Agriculture Forest Service NE Forest Experimental Station General Technical Bulletin NE-211; U.S. Department of Agriculture: Washington, DC, USA, $1995 ;$ p. 34.

2. Milanović, S.; Lazarević, J.; Popović, Z.; Miletić, Z.; Kostić, M.; Radulović, Z.; Karadžić, D.; Vuleta, A. Preference and performance of the larvae of Lymantria dispar (Lepidoptera: Lymantriidae) on three species of European oaks. Eur. J. Entomol. 2014, 111, 371-378. [CrossRef]

3. Naidoo, R.; Lechowicz, M.J. Effects of gypsy moth on radial growth of deciduous trees. For. Sci. 2001, 47, 338-348.

4. Fajvan, M.A.; Rentch, J.; Gottschalk, K. The effects of thinning and gypsy moth defoliation on wood volume growth in oaks. Trees 2008, 22, 257-268. [CrossRef]

5. Davidson, C.B.; Gottschalk, K.W.; Johnson, J.E. Tree mortality following defoliation by the European gypsy moth (Lymantria dispar L.) in the United States: A review. For. Sci. 1999, 45, 74-84.

6. Milanović, S.; Mihajlović, L.; Karadžić, D.; Jankovsky, L.; Aleksić, P.; Janković-Tomanić, M.; Lazarević, J. Effects of pedunculate oak tree vitality on gypsy moth preference and performance. Arch. Biol. Sci. 2014, 66, 1659-1672. [CrossRef]

7. Morin, R.S.; Liebhold, A.M. Invasive forest defoliator contributes to the impending downward trend of oak dominance in eastern North America. Forestry 2016, 89, 284-289. [CrossRef]

8. Arai, T.; Yaginuma, K.; Toyoshima, S.; Ito, T.; Takanashi, M. Damage of Lymantria dispar and Lymantria mathura aurora in apple orchards. Annu. Rep. Soc. Plant Prot. North Jpn. 2010, 61, 220-224.

9. Bigsby, K.M.; Ambrose, M.J.; Tobin, P.C.; Sills, E.O. The cost of gypsy moth sex in the city. Urban For. Urban Green. 2014, 13, 459-468. [CrossRef]

10. Stenersen, J. Chemical Pesticides Mode of Action and Toxicology, 1st ed.; CRC Press: Boca Raton, FL, USA, 2004.

11. Devine, G.J.; Furlong, M.J. Insecticide use: Contexts and ecological consequences. Agric. Hum. Values 2007, 24, 281-306. [CrossRef]

12. Guedes, R.N.C.; Walse, S.S.; Throne, J.E. Sublethal exposure, insecticide resistance, and community stress. Curr. Opin. Insect Sci. 2017, 21, 47-53. [CrossRef] [PubMed]

13. Brevik, K.; Schoville, S.D.; Mota-Sanchez, D.; Chen, Y.H. Pesticide durability and the evolution of resistance: A novel application of survival analysis. Pest Manag. Sci. 2018, 74, 1953-1963. [CrossRef]

14. Umina, P.A.; McDonald, G.; Maino, J.; Edwards, O.; Hoffmann, A.A. Escalating insecticide resistance in Australian grain pests: Contributing factors, industry trends and management opportunities. Pest Manag. Sci. 2019, 75, 1494-1506. [CrossRef]

15. Dar, M.A.; Kaushik, G.; Chiu, J.F.V. Pollution status and biodegradation of organophosphate pesticides in the environment. In Abatement of Environmental Pollutants; Singh, P., Kumar, A., Borthakur, A., Eds.; Elsevier: Amsterdam, The Netherlands, 2020; pp. 25-66.

16. Senthil-Nathan, S. A review of bio pesticides and their mode of action against insect pests. In Environmental Sustainability-Role of Green Technologies; Thangavel, P., Sridevi, G., Eds.; Springer: New Delhi, India, 2015; pp. 49-63.

17. Kumar, V. A review on efficacy of biopesticides to control the agricultural insect's pest. Int. J. Agric. Sci. Res. $2015,4,168-179$.

18. Anwer, M.A. Biopesticides and Bioagents: Novel Tools for Pest Management, 1st ed.; CRC Press: Boca Raton, FL, USA, 2017.

19. Isman, M.B. Commercial development of plant essential oils and their constituents as active ingredients in bioinsecticides. Phytochem. Rev. 2020, 19, 235-241. [CrossRef]

20. Stanković, S.; Kostić, M.; Kostić, I.; Krnjajić, S. Practical approaches to pest control: The use of natural compounds. In Pests, Weeds and Diseases in Agricultural Crop and Animal Husbandry Production; Kontogiannatos, D., Ed.; IntechOpen: London, UK, 2020.

21. Shahzad, K.; Manzoor, F. Nanoformulations and their mode of action in insects: A review of biological interactions. Drug Chem. Toxicol. 2021, 44, 1-11. [CrossRef] [PubMed]

22. Liebhold, A.; McManus, M. The evolving use of insecticides in gypsy moth management. J. For. 1999, 97, $20-23$.

23. Sharov, A.A.; Leonard, D.; Liebhold, A.M.; Roberts, E.A.; Dickerson, W. "Slow the spread": A national program to contain the gypsy moth. Forestry 2002, 100, 30-36.

24. Helson, B. Naturally derived insecticides: Prospects for forestry use. For. Chron. 1992, 68, 349-354. [CrossRef]

25. Norris, D.M.; Markovic, I. Ash Extractabels for Deterring Gypsy Moth. U.S. Patent No. 5,614,196, 25 March 1997. Available online: https: / / patentimages.storage.googleapis.com/1e/2d/2f/019e766c0d0db9/US5614196.pdf (accessed on 12 October 2021).

26. Hussein, R.A.; El-Anssary, A.A. Plants secondary metabolites: The key drivers of the pharmacological actions of medicinal plants. In Herbal Medicine; Builders, P.H., Ed.; IntechOpen: London, UK, 2019.

27. Khare, S.; Singh, N.B.; Singh, A.; Hussain, I.; Niharika, K.; Yadav, V.; Bano, C.; Yadav, R.K.; Amist, N. Plant secondary metabolites synthesis and their regulations under biotic and abiotic constraints. J. Plant Biol. 2020, 63, 203-216. [CrossRef]

28. Pavela, R. History, presence and perspective of using plant extracts as commercial botanical insecticides and farm products for protection against insects-A review. Plant Protect. Sci. 2016, 52, 229-241.

29. Isman, M.B.; Machial, C.M. Pesticides based on plant essential oils: From traditional practice to commercialization. In Advances in Phytomedicine; Rai, M., Carpinella, M.C., Eds.; Elsevier: Amsterdam, The Netherland, 2006; Volume 3, pp. $29-44$.

30. Tripathi, A.K.; Upadhyay, S.; Bhuiyan, M.; Bhattacharya, P.R. A review on prospects of essential oils as biopesticide in insect-pest management. J. Pharmacogn. Phytother. 2009, 1, 052-063. 
31. Nerio, L.S.; Olivero-Verbel, J.; Stashenko, E. Repellent activity of essential oils: A review. Bioresour. Technol. 2010, 101, 372-378. [CrossRef] [PubMed]

32. Zibaee, A. Botanical insecticides and their effects on insect biochemistry and immunity. In Pesticides in the Modern World-Pests Control and Pesticides Exposure and Toxicity Assessment; Stoytcheva, M., Ed.; IntechOpen: London, UK, 2011; pp. 55-68.

33. Isman, M.B.; Tak, J.H. Commercialization of insecticides based on plant essential oils: Past, present, and future. In Green Pesticides Handbook; Nollet, L.M.L., Rathore, H.S., Eds.; CRC Press: Boca Raton, FL, USA, 2017; pp. 27-40.

34. De Souza, M.A.; Da Silva, L.; Macêdo, M.J.F.; Lacerda-Neto, L.J.; dos Santos, M.A.C.; Coutinho, H.D.M.; Cunha, F.A.B. Adulticide and repellent activity of essential oils against Aedes aegypti (Diptera: Culicidae)-A review. S. Afr. J. Bot. 2019, 124, 160-165. [CrossRef]

35. Campos, E.V.R.; Proença, P.L.F.; Oliveira, J.L.; Bakshi, M.; Abhilash, P.C.; Fraceto, L.F. Use of botanical insecticides for sustainable agriculture: Future perspectives. Ecol. Indic. 2019, 105, 483-495. [CrossRef]

36. Isman, M.B. Botanical insecticides in the twenty-first century-Fulfilling their promise? Annu. Rev. Entomol. 2020, 65, 233-249. [CrossRef]

37. Benelli, G. On a magical mystery tour of green insecticide research: Current issues and challenges. Molecules 2020, 25, 5014. [CrossRef]

38. Spinozzi, E.; Maggi, F.; Bonacucina, G.; Pavela, R.; Boukouvala, M.C.; Kavallieratos, N.G.; Canale, A.; Romano, D.; Desneux, N.; Wilke, A.B.B.; et al. Apiaceae essential oils and their constituents as insecticides against mosquitoes-A review. Ind. Crops Prod. 2021, 171, 113892. [CrossRef]

39. Bruce, T.J.; Pickett, J.A. Perception of plant volatile blends by herbivorous insects-finding the right mix. Phytochemistry 2011, 72, 1605-1611. [CrossRef]

40. Deletre, E.; Schatz, B.; Bourguet, D.; Chandre, F.; Williams, L.; Ratnadass, A.; Martin, T. Prospects for repellent in pest control: Current developments and future challenges. Chemoecology 2016, 26, 127-142. [CrossRef]

41. Da Cunha, F.A.B.; Wallau, G.L.; Pinho, A.I.; Nunes, M.E.M.; Leite, N.F.; Tintino, S.R.; da Costa, G.M.; Athayde, M.L.; Boligon, A.A.; Coutinho, H.D.M.; et al. Eugenia uniflora leaves essential oil induces toxicity in Drosophila melanogaster: Involvement of oxidative stress mechanisms. Toxicol. Res. 2015, 4, 634-644. [CrossRef]

42. Shahriari, M.; Sahebzadeh, N.; Zibaee, A. Effect of Teucrium polium (Lamiaceae) essential oil on digestive enzyme activities and energy reserves of Ephestia kuehniella (Lepidoptera: Pyralidae). Invertebr. Surviv. J. 2017, 14, 182-189.

43. Benelli, G.; Pavela, R.; Petrelli, R.; Cappellacci, L.; Canale, A.; Senthil-Nathan, S.; Maggi, F. Not just popular spices! Essential oils from Cuminum cyminum and Pimpinella anisum are toxic to insect pests and vectors without affecting non-target invertebrates. Ind. Crops Prod. 2018, 124, 236-243. [CrossRef]

44. Hashem, A.S.; Awadalla, S.S.; Zayed, G.M.; Maggi, F.; Benelli, G. Pimpinella anisum essential oil nanoemulsions against Tribolium castaneum-Insecticidal activity and mode of action. Environ. Sci. Pollut. Res. 2018, 25, 18802-18812. [CrossRef]

45. Hashem, A.S.; Ramadan, M.M.; Abdel-Hady, A.A.; Sut, S.; Maggi, F.; Dall'Acqua, S. Pimpinella anisum essential oil nanoemulsion toxicity against Tribolium castaneum? Shedding light on its interactions with aspartate aminotransferase and alanine aminotransferase by molecular docking. Molecules 2020, 25, 4841. [CrossRef] [PubMed]

46. Castillo-Morales, R.M.; Otero, A.L.C.; Mendez-Sanchez, S.C.; Da Silva, M.A.N.; Stashenko, E.E.; Duque, J.E. Mitochondrial affectation, DNA damage and AChE inhibition induced by Salvia officinalis essential oil on Aedes aegypti larvae. Comp. Biochem. Physiol. C Toxicol. Pharmacol. 2019, 221, 29-37. [CrossRef] [PubMed]

47. Fergani, Y.A.; Elbanna, H.M.; Hamama, H.M. Genotoxicity of some plant essential oils in cotton leafworm, Spodopteralittoralis (Lepidoptera: Noctuidae): The potential role of detoxification enzymes. Egypt. J. Zool. 2020, 73, 53-66. [CrossRef]

48. Milanović, S.D.; Popović, M.M.; Dobrosavljević, J.N.; Kostić, I.M.; Lazarević, J.M. Desperate times call for desperate measures: Short-term use of the common ash tree by gypsy moth larvae (Lepidoptera: Erebidae) under density and starvation stress. Arch. Biol. Sci. 2020, 72, 63-69. [CrossRef]

49. Chen, Y.Z.; Zhang, B.W.; Yang, J.; Zou, C.S.; Li, T.; Zhang, G.C.; Chen, G.S. Detoxification, antioxidant, and digestive enzyme activities and gene expression analysis of Lymantria dispar larvae under carvacrol. J. Asia-Pac. Entomol. 2021, 24, 208-216. [CrossRef]

50. Nasr, E.E.; Teleb, S.S.; Abou-Saty, A.I. Nutritional responses of the black cutworm, Agrotis ipsilon (Hufn.), larvae under toxicity effects of five wild botanical extracts from Sinai, Egypt. Annu. Res. Rev. Biol. 2021, 36, 30-46. [CrossRef]

51. Haddi, K.; Turchen, L.M.; Viteri Jumbo, L.O.; Guedes, R.N.; Pereira, E.J.; Aguiar, R.W.; Oliveira, E.E. Rethinking biorational insecticides for pest management: Unintended effects and consequences. Pest Manag. Sci. 2020, 76, 2286-2293. [CrossRef]

52. Evergetis, E.; Michaelakis, A.N.; Haroutounian, S.A. Essential oils of Umbelliferae (Apiaceae) family taxa as emerging potent agents for mosquito control. In Integrated Pest Management and Pest Control_Currentand Future Tactics; Larramendy, M.L., Soloneski, S., Eds.; IntechOpen: Rijeka, Croatia, 2012; Chapter 26; pp. 613-638.

53. Yeom, H.J.; Kang, J.S.; Kim, G.H.; Park, I.K. Insecticidal and acetylcholine esterase inhibition activity of Apiaceae plant essential oils and their constituents against adults of German cockroach (Blattella germanica). J. Agric. Food Chem. 2012, 60, 7194-7203. [CrossRef]

54. Ebadollahi, A. Plant essential oils from Apiaceae family as alternatives to conventional insecticides. Ecol. Balk. $2013,5,149-172$. 
55. Sousa, R.M.O.; Rosa, J.S.; Oliveira, L.; Cunha, A.; Fernandes-Ferreira, M. Activities of Apiaceae essential oils and volatile compounds on hatchability, development, reproduction and nutrition of Pseudaletia unipuncta (Lepidoptera: Noctuidae). Ind. Crops Prod. 2015, 63, 226-237. [CrossRef]

56. Camilo, C.J.; Alves Nonato, C.D.F.; Galvão-Rodrigues, F.F.; Costa, W.D.; Clemente, G.G.; Sobreira Macedo, M.A.C.; Galvão Rodrigues, F.F.; da Costa, J.G.M. Acaricidal activity of essential oils: A review. Trends Phytochem. Res. 2017, 1, 183-198.

57. Benelli, G.; Pavela, R. Repellence of essential oils and selected compounds against ticks-A systematic review. Acta Trop. 2018, 179, 47-54. [CrossRef]

58. Chaubey, M.K. Essential oils as green pesticides of stored grain insects. Eur. J. Biol. Res. 2019, 9, $202-244$.

59. Ikbal, C.; Pavela, R. Essential oils as active ingredients of botanical insecticides against aphids. J. Pest Sci. 2019, 92, 971-986. [CrossRef]

60. Pavela, R.; Morshedloo, M.R.; Mumivand, H.; Khorsand, G.J.; Karami, A.; Maggi, F.; Desneux, N.; Benelli, G. Phenolic monoterpene-rich essential oils from Apiaceae and Lamiaceae species: Insecticidal activity and safety evaluation on non-target earthworms. Entomol. Gen. 2020, 40, 421-435. [CrossRef]

61. Sousa, R.M.O.; Cunha, A.C.; Fernandes-Ferreira, M. The potential of Apiaceae species as sources of singular phytochemicals and plant-based pesticides. Phytochemistry 2021, 187, 112714. [CrossRef] [PubMed]

62. Muturi, E.J.; Doll, K.; Ramirez, J.L.; Rooney, A.P. Bioactivity of wild carrot (Daucus carota, Apiaceae) essential oil against mosquito larvae. J. Med. Entomol. 2019, 56, 784-789. [CrossRef]

63. Kostić, I.; Petrović, O.; Milanović, S.; Popović, Z.; Stanković, S.; Todorović, G.; Kostić, M. Biological activity of essential oils of Athamanta haynaldii and Myristica fragrans to gypsy moth larvae. Ind. Crops Prod. 2013, 41, 17-20. [CrossRef]

64. Mossa, A.T.H. Green pesticides: Essential oils as biopesticides in insect-pest management. J. Environ. Sci. Technol. 2016, 9, 354. [CrossRef]

65. Pavela, R.; Benelli, G. Essential oils as ecofriendly biopesticides? Challenges and constraints. Trends Plant Sci. 2016, 21, 1000-1007. [CrossRef]

66. Rocha, D.K.; Matos, O.; Novo, M.T.; Figueiredo, A.C.; Delgado, M.; Moiteiro, C. Larvicidal activity against Aedes aegypti of Foeniculum vulgare essential oils from Portugal and Cape Verde. Nat. Prod. Commun. 2015, 10, 677-682. [CrossRef]

67. Pavela, R.; Žabka, M.; Bednář, J.; Tř́íska, J.; Vrchotová, N. New knowledge for yield, composition and insecticidal activity of essential oils obtained from the aerial parts or seeds of fennel (Foeniculum vulgare Mill.). Ind. Crops Prod. 2016, 83, $275-282$. [CrossRef]

68. Skuhrovec, J.; Douda, O.; Zouhar, M.; Maňasová, M.; Božik, M.; Klouček, P. Insecticidal and behavioral effect of microparticles of Pimpinella anisum essential oil on larvae of Leptinotarsa decemlineata (Coleoptera: Chrysomelidae). J. Econom. Entomol. 2020, 113, 255-262. [CrossRef]

69. Lazarević, J.; Jevremović, S.; Kostić, I.; Kostić, M.; Vuleta, A.; Manitašević Jovanović, S.; Šešlija Jovanović, D. Toxic, oviposition deterrent and oxidative stress effects of Thymus vulgaris essential oil against Acanthoscelides obtectus. Insects 2020, 11, 563. [CrossRef]

70. Moretti, M.D.; Sanna-Passino, G.; Demontis, S.; Bazzoni, E. Essential oil formulations useful as a new tool for insect pest control. AAPS PharmSciTech 2002, 3, 64-74. [CrossRef]

71. Cetin, H.; Erler, F.; Yanikoglu, A. A comparative evaluation of Origanum onites essential oil and its four major components as larvicides against the pine processionary moth, Thaumetopoea wilkinsoni Tams. Pest Manag. Sci. 2007, 63, 830-833. [CrossRef] [PubMed]

72. Gupta, A.; Sharma, S.; Naik, S.N. Biopesticidal value of selected essential oils against pathogenic fungus, termites, and nematodes. Int. Biodeter. Biodegr. 2011, 65, 703-707. [CrossRef]

73. Ezzine, O.; Dhahri, S.; Akkari, H.; Ben Jamâa, M.L. Larvicidal activity of essential oil of Mentha pulegium on larvae of Orgyia trigotephras Boisduval, 1829 (Lepidoptera, Erebidae). J. New Sci. 2018, 20, 3423-3428.

74. Devrnja, N.; Kostić, I.; Lazarević, J.; Savić, J.; Ćalić, D. Evaluation of tansy essential oil as a potential "green" alternative for gypsy moth control. Environ. Sci. Pollut. Res. 2020, 27, 11958-11967. [CrossRef] [PubMed]

75. Kostić, M.; Popović, Z.; Brkić, D.; Milanović, S.; Sivčev, I.; Stanković, S. Larvicidal and antifeedant activity of some plant-derived compounds to Lymantria dispar L. (Lepidoptera: Limantriidae). Bioresour. Technol. 2008, 99, 7897-7901. [CrossRef] [PubMed]

76. Popović, Z.; Kostić, M.; Stanković, S.; Milanović, S.; Sivčev, I.; Kostić, I.; Kljajić, P. Ecologically acceptable usage of derivatives of essential oil of sweet basil, Ocimum basilicum, as antifeedants against larvae of the gypsy moth, Lymantria dispar. J. Insect Sci. 2013, 13, T161. [CrossRef] [PubMed]

77. Gvozdenac, S.M.; Inđić, D.V.; Vuković, S.M.; Grahovac, M.S.; Tanasković, S.T. Antifeeding activity of several plant extracts against Lymantria dispar L. (Lepidoptera: Lymantriidae) larvae. Pestic. Phytomed. 2012, 27, 305-311. [CrossRef]

78. Işıkber, A.A.; Özder, N.; Sağlam, Ö. Susceptibility of eggs of Tribolium confusum, Ephestia kuehniella and Plodia interpunctella to four essential oil vapors. Phytoparasitica 2009, 37, 231. [CrossRef]

79. Karahroodi, Z.R.; Moharramipour, S.; Rahbarpour, A. Investigated repellency effect of some essential oils of 17 native medicinal plants on adults Plodia interpunctella. Am.-Eurasian J. Sustain. Agric. 2009, 3, 181-185.

80. Elumalai, K.; Krishnappa, K.; Anandan, A.; Govindarajan, M.; Mathivanan, T. Larvicidal and ovicidal activity of seven essential oil against lepidopteran pest S. litura (Lepidoptera: Noctuidae). Int. J. Recent Sci. Res. 2010, 1, 8-14. 
81. Sousa, R.M.O.; Rosa, J.S.; Oliveira, L.; Cunha, A.; Fernandes-Ferreira, M. Activities of Apiaceae essential oils against armyworm, Pseudaletia unipuncta (Lepidoptera: Noctuidae). J. Agric. Food Chem. 2013, 61, 7661-7672. [CrossRef] [PubMed]

82. Chantawee, A.; Soonwera, M. Larvicidal, pupicidal and oviposition deterrent activities of essential oils from Umbelliferae plants against house fly Musca domestica. Asian Pac. J. Trop. Med. 2018, 11, 621. [CrossRef]

83. Pavela, R. Screening of Eurasian plants for insecticidal and growth inhibition activity against Spodoptera littoralis larvae. Afr. J. Agric. Res. 2011, 6, 2895-2907.

84. Oviedo-Sarmiento, J.S.; Cortes, J.J.B.; Ávila, W.A.D.; Suárez, L.E.C.; Daza, E.H.; Patiño-Ladino, O.J.; Prieto-Rodríguez, J.A. Fumigant toxicity and biochemical effects of selected essential oils toward the red flour beetle, Tribolium castaneum (Coleoptera: Tenebrionidae). Pestic. Biochem. Physiol. 2021, 104941. [CrossRef]

85. Szczepanik, M.; Dams, I.; Wawrzeńczyk, C. Feeding deterrent activity of terpenoid lactones with the p-menthane system against the Colorado potato beetle (Coleoptera: Chrysomelidae). Environ. Entomol. 2005, 34, 1433-1440. [CrossRef]

86. Nawrot, J.; Dams, I.; Wawrzeńczyk, C. Feeding deterrent activity of terpenoid lactones with a p-menthane system against stored-product pests. J. Stored Prod. Res. 2009, 45, 221-225. [CrossRef]

87. Kanda, D.; Kaur, S.; Koul, O. A comparative study of monoterpenoids and phenylpropanoids from essential oils against stored grain insects: Acute toxins or feeding deterrents. J. Pest Sci. 2017, 90, 531-545. [CrossRef]

88. Morgan, E.D. Azadirachtin, a scientific gold mine. Bioorg. Med. Chem. 2009, 17, 4096-4105. [CrossRef]

89. Mello, C.B.; Uzeda, C.D.; Bernardino, M.V.; Mendonça-Lopes, D.; Kelecom, A.; Fevereiro, P.C.; Guerra, M.S.; Oliveira, A.P.; Rocha, L.M.; Gonzalez, M.S. Effects of the essential oil obtained from Pilocarpus spicatus Saint-Hilaire (Rutaceae) on the development of Rhodnius prolixus nymphae. Rev. Bras. Farmacogn. 2007, 17, 514-520. [CrossRef]

90. Oliveira, A.P.; Rodrigo, A.S.; Botas, G.S.; Gonzalez, M.S.; Santos, M.G.; Teixeira, L.A.; Rocha, L.M. Chemical and biological investigations of Pilocarpus spicatus essential oils. Boletín Latinoam. Caribe Plantas Med. Aromáticas 2010, 9, $206-211$.

91. Qin, W.; Huang, S.; Li, C.; Chen, S.; Peng, Z. Biological activity of the essential oil from the leaves of Piper sarmentosum Roxb. (Piperaceae) and its chemical constituents on Brontispa longissima (Gestro) (Coleoptera: Hispidae). Pestic. Biochem. Physiol. 2010, 96, 132-139. [CrossRef]

92. Ghoneim, K.; Amer, M.; Al-Daly, A.; Mohammad, A.; Khadrawy, F.; Mahmoud, M.A. Disturbed acid and alkaline phosphatase activities in desert locust Schistocerca gregaria (Forskal) (Orthoptera: Acrididae) by extracts from the khella plant Ammi visnaga L. (Apiaceae). Int. J. Adv. Res. 2014, 2, 584-596.

93. Hummelbrunner, L.A.; Isman, M.B. Acute, sublethal, antifeedant, and synergistic effects of monoterpenoid essential oil compounds on the tobacco cutworm, Spodoptera litura (Lep., Noctuidae). J. Agric. Food Chem. 2001, 49, 715-720. [CrossRef]

94. Pavela, R. Acute toxicity and synergistic and antagonistic effects of the aromatic compounds of some essential oils against Culexquinquefasciatus Say larvae. Parasitol. Res. 2015, 114, 3835-3853. [CrossRef] [PubMed]

95. Cruz, G.S.; Wanderley-Teixeira, V.; da Silva, L.M.; Dutra, K.A.; Guedes, C.A.; de Oliveira, J.V.; Navarro, D.M.A.F.; Araújo, B.C.; Teixeira, Á.A.C. Chemical composition and insecticidal activity of the essential oils of Foeniculum vulgare Mill., Ocimum basilicum L., Eucalyptus staigeriana F. Muell. ex Bailey, Eucalyptus citriodora Hook and Ocimum gratissimum L. and their major components on Spodoptera frugiperda (Lepidoptera: Noctuidae). J. Essent. Oil-Bear. Plants 2017, 20, 1360-1369.

96. Zahran, H.E.D.M.; Abdelgaleil, S.A. Insecticidal and developmental inhibitory properties of monoterpenes on Culex pipiens L. (Diptera: Culicidae). J. Asia-Pac. Entomol. 2011, 14, 46-51. [CrossRef]

97. Al-Nagar, N.M.; Abou-Taleb, H.K.; Shawir, M.S.; Abdelgaleil, S.A. Comparative toxicity, growth inhibitory and biochemical effects of terpenes and phenylpropenes on Spodoptera littoralis (Boisd.). J. Asia-Pac. Entomol. 2020, 23, 67-75. [CrossRef]

98. Sohail, M.; Aqueel, M.A.; Dai, P.; Ellis, J.D. The larvicidal and adulticidal effects of selected plant essential oil constituents on greater wax moths. J. Econom. Entomol. 2021, 114, 397-402. [CrossRef] [PubMed]

99. Regnault-Roger, C.; Hamraoui, A. Fumigant toxic activity and reproductive inhibition induced by monoterpenes on Acanthoscelides obtectus (Say) (Coleoptera), a bruchid of kidney bean (Phaseolus vulgaris L.). J. Stored Prod. Res. 1995, 31, 291-299. [CrossRef]

100. Céspedes, C.L.; Ortega, C.; Alarcon, J.; Salazar, J.R. Antifeedant, feeding deterrent and insect growth regulatory effects of Calceolaria integrifolia sensu lato complex: C. integrifolia $x$ talcana (Scrophulariaceae). Rev. Latinoamer. Quim. 2014, 42, 113-132.

101. Céspedes, C.L.; Alarcon, J.E.; Aqueveque, P.; Seigler, D.S.; Kubo, I. In the search for new secondary metabolites with biopesticidal properties. Isr. J. Plant Sci. 2015, 62, 216-228. [CrossRef]

102. Mann, R.S.; Kaufman, P.E. Natural product pesticides: Their development, delivery and use against insect vectors. Mini-Rev. Org. Chem. 2012, 9, 185-202. [CrossRef]

103. Pavela, R. Acute, synergistic and antagonistic effects of some aromatic compounds on the Spodoptera littoralis Boisd. (Lep., Noctuidae) larvae. Ind. Crops Prod. 2014, 60, 247-258. [CrossRef]

104. Gaire, S.; Scharf, M.E.; Gondhalekar, A.D. Synergistic toxicity interactions between plant essential oil components against the common bed bug (Cimex lectularius L.). Insects 2020, 11, 133. [CrossRef]

105. Aungtikun, J.; Soonwera, M.; Sittichok, S. Insecticidal synergy of essential oils from Cymbopogon citratus (Stapf.), Myristica fragrans (Houtt.), and Illicium verum Hook. f. and their major active constituents. Ind. Crops Prod. 2021, 164, 113386. [CrossRef]

106. Kostyukovsky, M.; Rafaeli, A.; Gileadi, C.; Demchenko, N.; Shaaya, E. Activation of octopaminergic receptors by essential oil constituents isolated from aromatic plants: Possible mode of action against insect pests. Pest Manag. Sci. 2002, 58, 1101-1106. [CrossRef] [PubMed] 
107. López, M.D.; Pascual-Villalobos, M.J. Mode of inhibition of acetylcholinesterase by monoterpenoids and implications for pest control. Ind. Crops Prod. 2010, 31, 284-288. [CrossRef]

108. Jankowska, M.; Rogalska, J.; Wyszkowska, J.; Stankiewicz, M. Molecular targets for components of essential oils in the insect nervous system-A review. Molecules 2018, 23, 34. [CrossRef] [PubMed]

109. Shahriari, M.; Zibaee, A.; Sahebzadeh, N.; Shamakhi, L. Effects of $\alpha$-pinene, trans-anethole, and thymol as the essential oil constituents on antioxidant system and acetylcholine esterase of Ephestia kuehniella Zeller (Lepidoptera: Pyralidae). Pestic. Biochem. Physiol. 2018, 150, 40-47. [CrossRef]

110. Bloomquist, J.R.; Boina, D.R.; Chow, E.; Carlier, P.R.; Reina, M.; Gonzalez-Coloma, A. Mode of action of the plant-derived silphinenes on insect and mammalian GABAA receptor/chloride channel complex. Pestic. Biochem. Physiol. 2008, 91, 17-23. [CrossRef]

111. Drijfhout, F.P.; Morgan, E.D.; Liu, H.W.; Mander, L. Terrestrial natural products as antifeedants. In Comprehensive Natural Products II; Liu, H.-W., Mander, L., Eds.; Elsevier: Oxford, UK, 2010; pp. 457-501.

112. Santana, O.; Andres, M.F.; Sanz, J.; Errahmani, N.; Abdeslam, L.; González-Coloma, A. Valorization of essential oils from Moroccan aromatic plants. Nat. Prod. Commun. 2014, 9, 1109-1114. [CrossRef]

113. Petrović, M.; Popović, A.; Kojić, D.; Šućur, J.; Bursić, V.; Aćimović, M.; Malenčić, Đ.; Stojanović, T.; Vuković, G. Assessment of toxicity and biochemical response of Tenebrio molitor and Tribolium confusum exposed to Carum carvi essential oil. Entomol. Gen. 2019, 38, 333-348. [CrossRef]

114. Shahriari, M.; Zibaee, A.; Shamakhi, L.; Sahebzadeh, N.; Naseri, D.; Hoda, H. Bio-efficacy and physiological effects of Eucalyptus globulus and Allium sativum essential oils against Ephestia kuehniella Zeller (Lepidoptera: Pyralidae). Toxin Rev. 2019, 39, 422-433. [CrossRef]

115. El-Naggar, S.A.F.; Doskotch, R.W.; ODell, T.M.; Girard, L. Antifeedant diterpenes for the gypsy moth larvae from Kalmia latifolia: Isolation and characterization of ten grayanoids. J. Nat. Prod. 1980, 43, 617-631. [CrossRef]

116. Powell, J.S.; Raffa, K.F. Effects of selected Larix laricina terpenoids on Lymantria dispar (Lepidoptera: Lymantriidae) development and behavior. Environ. Entomol. 1999, 28, 148-154. [CrossRef]

117. Rharrabe, K.; Amri, H.; Bouayad, N.; Sayah, F. Effects of azadirachtin on post-embryonic development, energy reserves and $\alpha$-amylase activity of Plodia interpunctella Hübner (Lepidoptera: Pyralidae). J. Stored Prod. Res. 2008, 44, 290-294. [CrossRef]

118. Khosravi, R.; Sendi, J.J. Effect of neem pesticide (Achook) on midgut enzymatic activities and selected biochemical compounds in the hemolymph of lesser mulberry pyralid, Glyphodes pyloalis Walker (Lepidoptera: Pyralidae). J. Plant Prot. Res. 2013, 53, 238-247. [CrossRef]

119. Bezzar-Bendjazia, R.; Kilani-Morakchi, S.; Maroua, F.; Aribi, N. Azadirachtin induced larval avoidance and antifeeding by disruption of food intake and digestive enzymes in Drosophila melanogaster (Diptera: Drosophilidae). Pestic. Biochem. Physiol. 2017, 143, 135-140. [CrossRef]

120. Shu, B.; Zhang, J.; Cui, G.; Sun, R.; Yi, X.; Zhong, G. Azadirachtin affects the growth of Spodoptera litura Fabricius by inducing apoptosis in larval midgut. Front. Physiol. 2018, 9, 137. [CrossRef]

121. Kaur, M.; Saraf, I.; Kumar, R.; Singh, I.P.; Kaur, S. Bioefficacy of hexane extract of Inula racemosa (Asteraceae) against Spodoptera litura (Lepidoptera: Noctuidae). Gesunde Pflanz. 2019, 71, 165-174. [CrossRef]

122. Mojarab-Mahboubkar, M.; Sendi, J.J.; Aliakbar, A. Effect of Artemisia annua L. essential oil on toxicity, enzyme activities, and energy reserves of cotton bollworm Helicoverpa armigera (Hübner) (Lepidoptera: Noctuidae). J. Plant Prot. Res. 2015, 55, 371-377. [CrossRef]

123. Kiran, S.; Kujur, A.; Patel, L.; Ramalakshmi, K.; Prakash, B. Assessment of toxicity and biochemical mechanisms underlying the insecticidal activity of chemically characterized Boswellia carterii essential oil against insect pest of legume seeds. Pestic. Biochem. Physiol. 2017, 139, 17-23.

124. De Souza Alves, M.; Campos, I.M.; de Brito, D.D.M.C.; Cardoso, C.M.; Pontes, E.G.; de Souza, M.A.A. Efficacy of lemongrass essential oil and citral in controlling Callosobruchus maculatus (Coleoptera: Chrysomelidae), a post-harvest cowpea insect pest. Crop. Protect. 2019, 119, 191-196. [CrossRef]

125. Chintalchere, J.M.; Dar, M.A.; Shaha, C.; Pandit, R.S. Impact of essential oils on Musca domestica larvae: Oxidative stress and antioxidant responses. Int. J. Trop. Insect Sci. 2021, 41, 821-830. [CrossRef]

126. Vahabi Mashhoor, M.; Mikani, A.; Mehrabadi, M.; Moharramipour, S. Antifeedant activity of nanoemulsion formulation of arugula Eruca sativa oil on elm leaf beetle Xanthogaleruca luteola (Coleoptera: Chrysomelidae). J. Agric. Sci. Technol. 2021, 23, 125-136.

127. Valizadeh, B.; Sendi, J.J.; Zibaee, A.; Oftadeh, M. Effect of Neem based insecticide Achook®on mortality, biological and biochemical parameters of elm leaf beetle Xanthogaleruca luteola (Col.: Chrysomelidae). J. Crop. Protect. 2013, 2, 319-330.

128. Zhang, J.; Sun, T.; Sun, Z.; Li, H.; Qi, X.; Zhong, G.; Yi, X. Azadirachtin acting as a hazardous compound to induce multiple detrimental effects in Drosophila melanogaster. J. Hazard. Mater. 2018, 359, 338-347. [CrossRef]

129. Shahriari, M.; Sahbzadeh, N.; Zibaee, A.; Khani, A.; Senthil-Nathan, S. Metabolic response of Ephestia kuehniella Zeller (Lepidoptera: Pyralidae) to essential oil of Ajwain and thymol. Toxin. Rev. 2017, 36, 204-209. [CrossRef]

130. Jayakumar, M.; Ramachandran, M.; Krishnaveni, T.; Nattudurai, G. Toxicity and biochemical effects of essential oils of Anethumgraveolens L. and Melaleuca cajuputi Powell against Rhyzopertha dominica (F.) (Coleoptera: Bostrichidae). Int. J. Trop. Insect. Sci 2021, 41, 945-951. [CrossRef] 
131. Piri, A.; Sahebzadeh, N.; Zibaee, A.; Sendi, J.J.; Shamakhi, L.; Shahriari, M. Toxicity and physiological effects of ajwain (Carum copticum, Apiaceae) essential oil and its major constituents against Tuta absoluta (Meyrick) (Lepidoptera: Gelechiidae). Chemosphere 2020, 256, 127103. [CrossRef] [PubMed]

132. Yu, S.J. Microsomal oxidation of allelochemicals in generalist (Spodoptera frugiperda) and semispecialist (Anticarsiagemmatalis) insect. J. Chem. Ecol. 1987, 13, 423-436. [CrossRef] [PubMed]

133. Moldenke, A.F.; Berry, R.E.; Miller, J.C.; Kelsey, R.G.; Wernz, J.G.; Venkateswaran, S. Carbaryl susceptibility and detoxication enzymes in gypsy moth (Lepidoptera: Lymantriidae): Influence of host plant. J. Econ. Entomol. 1992, 85, 1628-1635. [CrossRef]

134. European Directorate for the Quality of Medicines. Determination of essential oils in vegetable drugs. In Europea Pharmacopoea, 4th ed.; Council of Europe Editions; European Directorate for the Quality of Medicines: Strasbourg, France, 2002 ; pp. 183-184.

135. Adams, R.P. Identification of Essential Oil Compounds by Gas Chromatography and Mass Spectrometry, 4th ed.; Allured Publishing Corporation: Carol Stream, IL, USA, 2009.

136. Markovic, I.; Norris, D.M.; Nordheim, E.V. Gypsy moth (Lymantria dispar) larval development and survival to pupation on diet plus extractables from green ash foliage. Entomol. Exp. Appl. 1997, 84, 247-254. [CrossRef]

137. Mostafiz, M.M.; Shim, J.K.; Hwang, H.S.; Bunch, H.; Lee, K.Y. Acaricidal effects of methyl benzoate against Tetranychus urticae Koch (Acari: Tetranychidae) on common crop plants. Pest Manag. Sci. 2020, 76, 2347-2354. [CrossRef]

138. Wilcox, D.; Dove, B.; McDavid, D.; Greer, D. Image Tool Copyright UTHSCSA 1996-2002; University of Texas Health Science Center (UTHSCSA): San Antonio, TX, USA, 1996.

139. Szczepanik, M.; Szumny, A.; Wawrzenczyk, C. The effect of $\alpha$-methylene lactone group on the feeding deterrent activity of natural and synthetic alkenes against Colorado Potato Beetle, Leptinotarsa decemlineata Say. Pol. J. Environ. Stud. 2009, 18, 1107-1112.

140. Waldbauer, G.P. The consumption and utilization of food by insects. Adv. Insect Phys. 1968, 5, $229-288$.

141. Scriber, J.M.; Slansky Jr, F. The nutritional ecology of immature insects. Annu. Rev. Entomol. 1981, 26, 183-211. [CrossRef]

142. Farrar, R.R.; Barbour, J.D.; Kennedy, G.G. Quantifying food consumption and growth in insects. Ann. Entomol. Soc. Am. 1989, 82, 593-598. [CrossRef]

143. McDonald, J.H. Handbook of Biological Statistics; Sparky House Publishing: Baltimore, MD, USA, 2014.

144. Brunner, E.; Puri, M.L. Nonparametric methods in factorial designs. Stat. Pap. 2001, 42, 1-52. [CrossRef]

145. Lichtenstein, E.P.; Liang, T.T.; Schulz, K.R.; Schnoes, H.K.; Carter, G.T. Insecticidal and synergistic components isolated from dill plants. J. Agric. Food Chem. 1974, 22, 658-664. [CrossRef]

146. He, W.; Huang, B. A review of chemistry and bioactivities of a medicinal spice: Foeniculum vulgare. J. Med. Plants Res. 2011, 5, 3595-3600.

147. Pavela, R. Essential oils from Foeniculum vulgare Miller as a safe environmental insecticide against the aphid Myzus persicae Sulzer. Environ. Sci. Pollut. Res. 2018, 25, 10904-10910. [CrossRef]

148. Kaur, V.; Kaur, R.; Bhardwaj, U. A review on dill essential oil and its chief compounds as natural biocide. Flavour Fragr. J. 2021, 36, 412-431. [CrossRef] 